\title{
Providing an Extension of the SCORM Standard to Support the Educational Contents Project for t-Learning
}

\author{
Francisco Miguel da Silva', Francisco Milton Mendes Neto', \\ Aquiles Medeiros Filgueira Burlamaqui' ${ }^{2}$ Karla Rosane do Amaral Demoly1, \\ João Phellipe de Freitas Pinto ${ }^{1}$ \\ ${ }^{1}$ Federal University of Semi Arid, Mossoró, Brazil \\ ${ }^{2}$ Federal University of Rio Grande do Norte, Natal, Brazil \\ Email: miguel.silva@ufersa.edu.br, miltonmendes@ufersa.edu.br, aquiles@natalnet.br, \\ karla.demoly@ufersa.edu.br, phellipe@ufersa.edu.br
}

Received 12 May 2015; accepted 23 June 2015; published 26 June 2015

Copyright (C) 2015 by authors and Scientific Research Publishing Inc.

This work is licensed under the Creative Commons Attribution International License (CC BY). http://creativecommons.org/licenses/by/4.0/

(c) (i) Open Access

\begin{abstract}
Nowadays, the Interactive Digital Television (iDTV) has promoted and increased the communication and interaction for knowledge, entertainment and recreation in Distance Education. The tLearning has been used as a new way of teaching and learning in the context of Learning Objects (LOs) assisting in electronic courses' development. With the fast e-Learning progress, some efforts to standardization have appeared enabling the educational contents' reusability and interoperability among systems. The most used standard is the Sharable Content Object Reference Model (SCORM). Therefore, this work is presenting the T-SCORM extension, which is aiming to adapt to the SCORM, thus improving the search and navigation of LOs with educational content for t-Learning. That will be done through an authoring tool named T-SCORM ADAPTER, and the final results will be showed in the application named T-SCORM-Moodle.
\end{abstract}

\section{Keywords}

iDTV, t-Learning, Learning Objects, SCORM, Extension

\section{Introduction}

Currently, there is a wide variety of e-Learning repositories providing digital resources for education such as Learning Objects (LOs). Some systems provide recommendation in order to assist users when searching for 
suitable LOs to their needs. LOs recommendation could be viewed as a single and unique task. However, the search for knowledge may influence people to acquire skills by making a particular person seek for new ways of learning. Usually, knowledge makes each person look for new ways of continuous improvement and increases the level of learning (Girardi, 2002).

According to Naidu (2006), e-Learning is mostly related to the intentional use of information and communication that are technologically connected in order to benefit the teaching-learning process. In other words, it refers basically to educational process using Information and Communication Technology to mediate both asynchronous and synchronous learning as well as teaching activities. Naidu (2006) also mentions other terms also used to describe this modality, such as virtual learning, distributed learning and network-web-based learning.

A major challenge nowadays is the computerized support to this activity. An important point in teaching attendance is the group activity. The students' interaction in order to develop some pedagogical task is very important in the learning process (Pontes, 2010). Currently, the advances in information and communication technologies have accelerated the Distance Education development, enabling the use of didactic content structured and more organized. According to Gazzoni et al. (2006), these contents may be available on the Web in different formats, such as hypertexts, videos, animations, etc.

Due to the fast e-Learning progress, many standardization efforts have emerged to enable the reusability of educational contents and interoperability among systems developed (Rey-Lopez et al., 2009). According to Shih, Yang, \& Tseng (2011), in order to share and reuse teaching content, many standards were proposed. And the Sharable Content Object Reference Model (SCORM) ${ }^{1}$ is the most used standard for learning content, once it brings in its context many standards of different standardization institutes in many fields of the e-Learning.

Based on this reality, there is the problem in how to adjust educational contents, so as to better support the search and navigation mechanism to make them available in the iDTV platform in order to present an effective and personalized learning. Another problem that arises in this context is how to make the Learning Objects $(\mathbf{L O s})^{2}$ become more suitable through their specification in SCORM, aiming at the proper presentation for iDTV.

In order to close that gap, this paper proposes to create an extension of SCORM standard improving the search, navigation and visualization for LOs with educational contents for $\mathrm{t}$-Learning ${ }^{3}$, thus making support more effective and better.

In addition to this introductory section, the paper first provides a description of the main features of iDTV and Distance Learning. Next, it presents the definitions of LOs as well as the standards for their development and description. Then, it exposes the details of our proposal and the authoring tools T-SCORM ADAPTER and TSCORM-Moodle. Then, it presents a case study with the technologies and languages used, also the final results of tests conducted and an analysis on the results found. After that, it presents and discusses similar approaches. Finally, it draws some conclusions and motivation for future work.

\section{Distance Learning and iDTV}

For decades the television is performing an educational role for the mass audience by broadcasting movies, documentaries and news as well as educational programs. The idea of Distance Learning through TV emerged extensively in particular as a complementary educational option besides PC-based e-Learning and traditional TV educational programs. iDTV education promises a huge potential due to its ability to support interactivity and the term of t-Learning prevailed for the definition of TV-based interactive learning (Bellotti, 2008). Today, iDTV platforms for learning provide a large amount of audiovisual and educational content to the viewer through interactive and content personalization. It is considered as the convergence of television and computer technologies by encompassing three important features typical of computer-based technologies (Lytras, Lougos, Chozos, \& Pouloudi, 2002), such as interactivity, personalization and digitization ${ }^{4}$.

According to Pazos-Arias et al. (2008), e-Learning and t-Learning have different approaches, considering the e-Learning being highly suitable in formal education environments. In (Bellotti et al., 2008), t-Learning course is consists of two main parts: broadcast video (i.e., the audiovisual stream) and the interactive application. These parts can be fully or semi synchronized in order to form a t-Learning course. In this section the structure of the

\footnotetext{
${ }^{1}$ http://www.adlnet.gov/capabilities/scorm.html

${ }^{2}$ LOs examples include multimedia and instructional content, and instructional software (Lucia, Azevedo, \& Anna, 2007).

${ }^{3} \mathrm{t}$-Learning is a shorthand meaning for TV-based interactive learning (Aarreniemi-Jokipelto, 2005).

${ }^{4}$ Conversion of an analogue signal or code into a digital signal or code. http://en.wikiversity.org/wiki/Digital_Libraries/Digitization
} 
interactive part of the course will be discussed and the synchronization with the video will be defined.

The proposed t-Learning course structure is shown in Figure 1.

\section{Learning Objects}

The Institute of Electrical and Electronics Engineers (IEEE) defines a Learning Object (LO) as "any entity, digital or non-digital, that may be used for learning, education or training (LTSC, 2002).

Adapting a definition from the Wisconsin Online Resource Center ${ }^{5}$, Beck (2008) suggests that LOs have the following key characteristics:

- Learning Objects - New way of thinking about learning content. Traditionally, content comes in a several hour chunk. Thus, smaller units of learning, typically ranging from 2 minutes to 15 minutes;

- Self-contained-Each learning object can be taken independently;

- Reusable - A single learning object may be used in multiple contexts for multiple purposes;

- Aggregated - Can be grouped into larger collections of content, including traditional course structures;

- Tagged with Metadata-Every LO has descriptive information allowing to be easily found by a search. According to Roebuck (2012), this is the information that may be included in a LOs and its metadata:

- General: Gather information in general, which describe the LO as a whole;

- Life Cycle: Gather features concerning to the history and Status Quo of the LO;

- Meta-Metadata: Collect information about the metadata instances;

- Technical: Gather the features and the technical requirements of LO;

- Educational: Collect the pedagogical and educational characteristics of LO;

- Rights: Describe Copyright And Other Restrictions;

- Relation: Define the relation characteristics among the LOs;

- Annotation: Comments regarding to educational use and information of LO;

- Classification: Describe the LO in relation to a classification of a specific system.

SCORM is a collection of standards and specifications for e-Learning. It defines communications between client side content and a host system (called "the run-time environment"), which is commonly supported by a Learning Management System (LMS) (ADL, 2010).

SCORM 2004 introduced a complex idea called sequencing, which is a set of rules that specifies the order in which a learner may experience content objects. In simple terms, they constrain a learner to a fixed set of paths through the training material, permit the learner to "bookmark" their progress when taking breaks, and assure the acceptability of test scores achieved by the learner. The standard uses XML to encode a file (imsmanifest.xml) that describes the components and resources.

The SCORM 2004 technical books and their acronyms are listed below:

- OV: SCORM 2004 2nd Edition Overview;

- CAM: SCORM Content Aggregation Model Version 1.3.1;

T-LEARNING COURSE

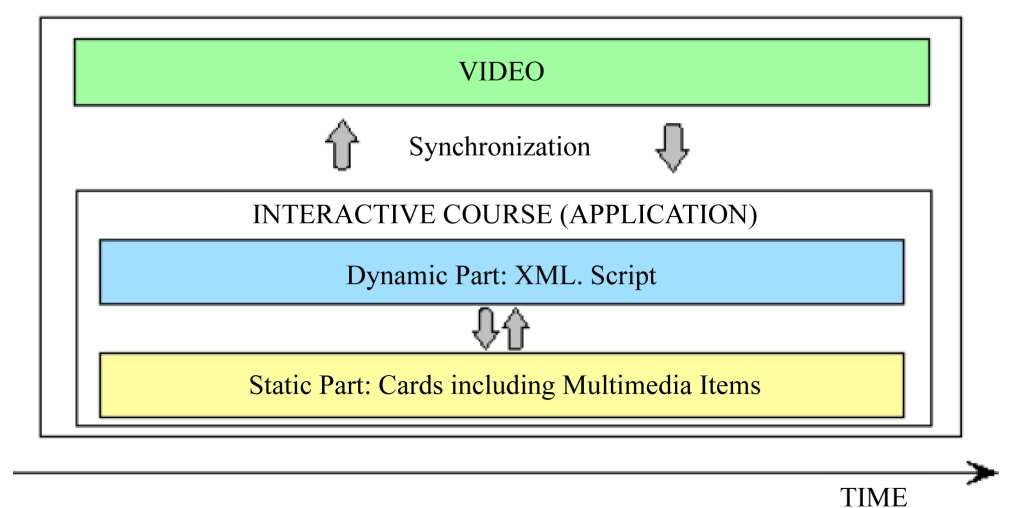

Figure 1. t-Learning course structure. Source: (Bellotti et al., 2008).

$\underline{5 \text { http://www.wisc-online.com/learn }}$ 
- RTE: SCORM Run-Time Environment Version 1.3.1;

- SN: SCORM Sequencing and Navigation Version 1.3.1;

- CR: SCORM Conformance Requirements Version 1.3;

- ADD: SCORM 2004 2nd Edition Addendum Version 1.2.

Enabling the content aggregation in a format that could be readable and transferable through systems on the Internet and being adopted ADL, the imsmanifest.xml is encoded in $\mathrm{xml}$ and it describes different components and resources. With markers for all the features of SCORM provided for the files configuration, also the locations of referenced files by these components.

Figure 2 shows a code example of imsmanifest.xml.

\section{Providing an Extension for the SCORM Standard}

As mentioned previously, the main goal of this paper is to improve is to provide an extension of the SCORM standard called T-SCORM, thus supporting the search and navigation making LOs available iDTV platform.

One of the benefit extension is to enable a system in order to search information contained in the LOs metadata with educational content which were specifically made for t-Learning within the imsmanifest.xml.

Assuming there is a LMS working making the selection and distribution of LOs for courses iniDTV platform in t-Learning context. Improve the selection process made by the LMS by adding a specific t-Learning information the LOs metadata will be the great challenge of this work.

T-SCORM extension is an adaptation of metadata information from SCORM standard based on $\mathbf{L O M}^{6}$ standard. Then, it has been proposed the addition of new elements giving more emphasis on the metadata information regardint to iDTV. With this, the LMS can manage in a quickly and efficient manne seeking and making these LOs available for students using iDTV platform, since is in accordance with their preferences and cognitive characteristics contained in their profiles.

\subsection{New Metadata Model}

Metadata is structured information that describes, explains, locates, or otherwise makes it easier to retrieve, use, or manage an information resource (NISO, 2004).

As a continuity of what has been proposed in this work, Silva et al. (2012) has created new metadata elements, making them child nodes in the main structure of LOM metadata model which SCORM is based on.

Adding these new elements in the LOM structure, it was possible to specify the LOs metadata with educational content for iDTV describing specific information for iDTV (interactivity level, copyright description, precise description on educational content in digital format, etc.).

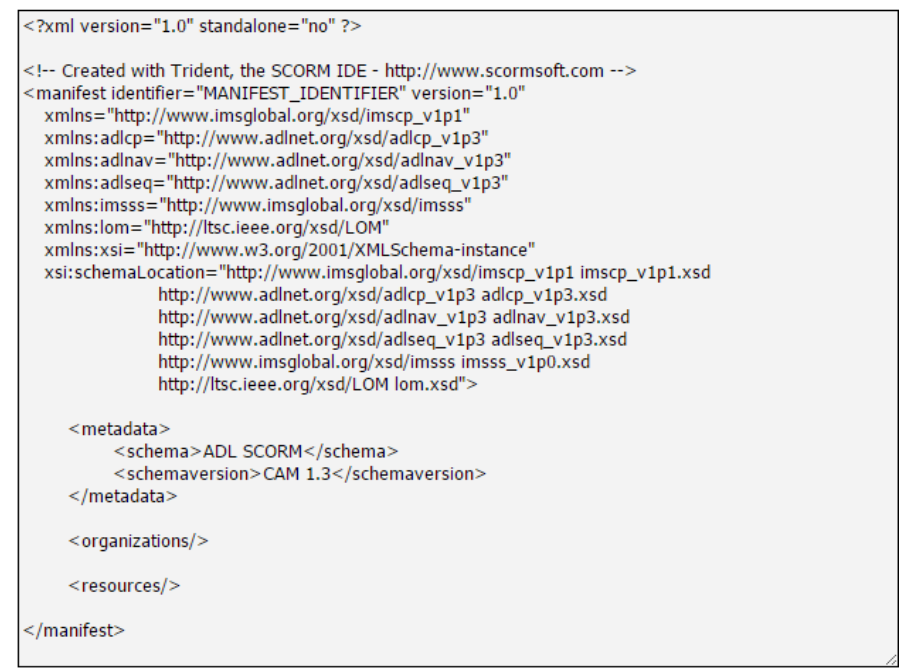

Figure 2. Structure and code of imsmanifest.xml.

${ }^{6} \mathrm{http}: / /$ grouper.ieee.org/groups/ltsc/wg12/20020612-Final-LOM-Draft.html 
In Figure 3, it is shown the overview of the new LOM structure proposed by (Silva et al., 2012).

It is possible to notice in blue the original metadata of LOM. In green, new categories of elements proposed by (Silva et al., 2012). And in orange, the final LOM's adaptation with the new metadata structure.

After the inclusion of these new elements adapted in the LOM structure, we twelve categories which that allow us to specify more precisely the LOs metadata with educational content for iDTV.

In Figure 4 will be explained how is distributed the main roles when applying the process of T-SCORM extension. First, we have the Vocabulary Creator that is in charge of adding the new elements, which shall contain the information regarding to the parameters of the new metadata.

The LO must be created and edited according to the specifications of SCORM standard. It has been used in this work the freeware tool Reload Editor for LO creation and editing

The Content Creator will add the T-SCORM extension using the T-SCORM ADAPTER, an authoring tool created by (Silva et al., 2012) and improved in this work. The tool reads the imsmanifest.xmland ensures that the extension receive the new metadata elements improving the classification and the specification of LOs with educational content for iDTV.

Finished this step, the T-SCORM ADAPTER will save the file with the changes with the new elements, but keeping the original structure (markers and header) of imsmanifest.xml, which is demanding for recognition by the LMS as a SCORM content package (Silva et al., 2012). In Figure 4 is shown the improved architecture created by (Silva et al., 2012) and how it applies the T-SCORM extension.

\subsection{Authoring Tool T-SCORM ADAPTER}

The T-SCORM ADAPTER tool was developed by (Silva et al., 2012) to facilitate the process of reading and adding the T-SCORM extension in the imsmanifest.xmlstructure.

The authoring tool was improved and in this paper it is presented with a new and friendly interface, which is practicable and easy to use, with tabs separated in an adequate manner to input the new information in order to compose the new LOs metadata for iDTV. See the new T-SCORM ADAPTER tool Figure 5.

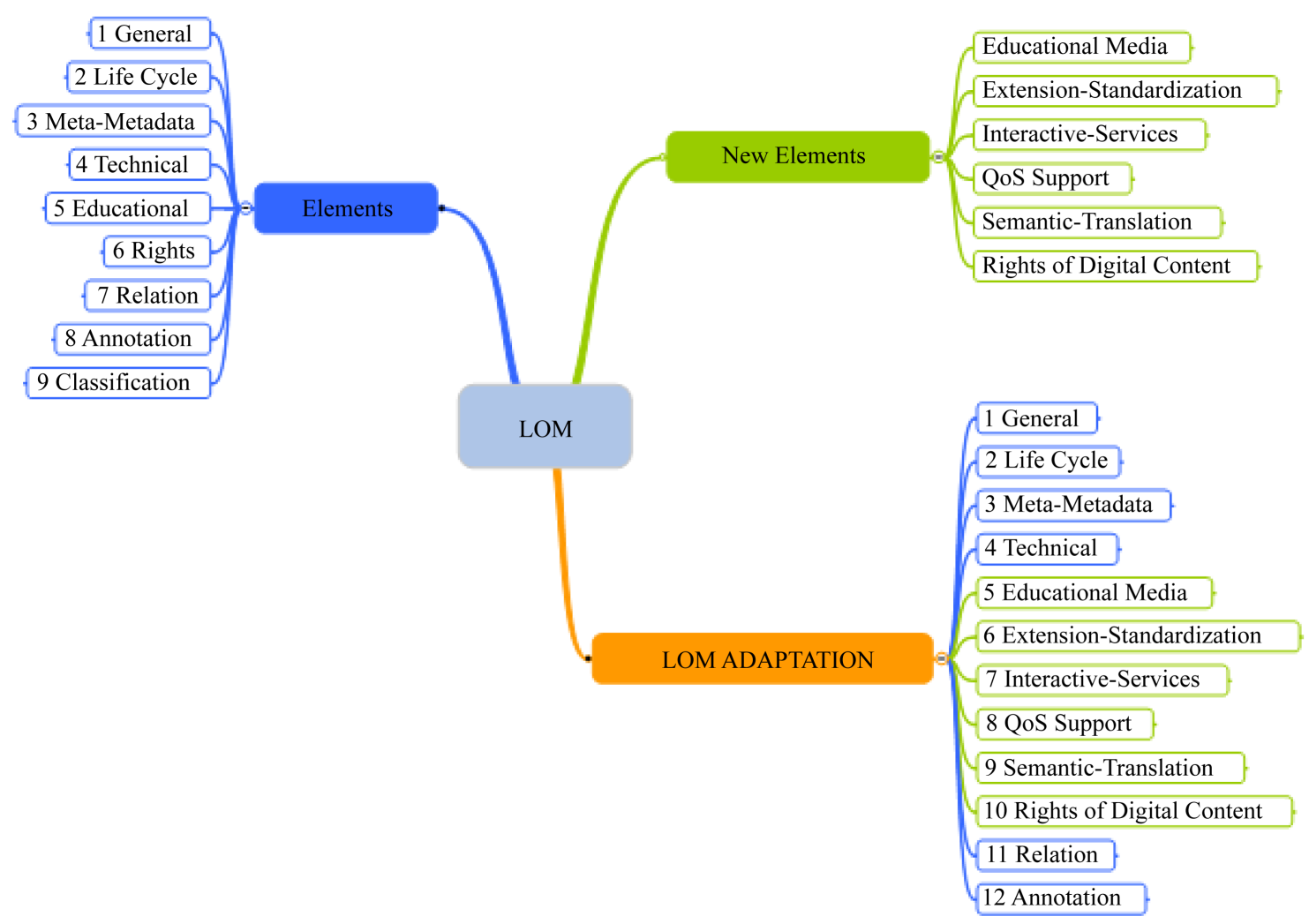

Figure 3. New LOM Structure for iDTV. Source: (Silva et al., 2012). 


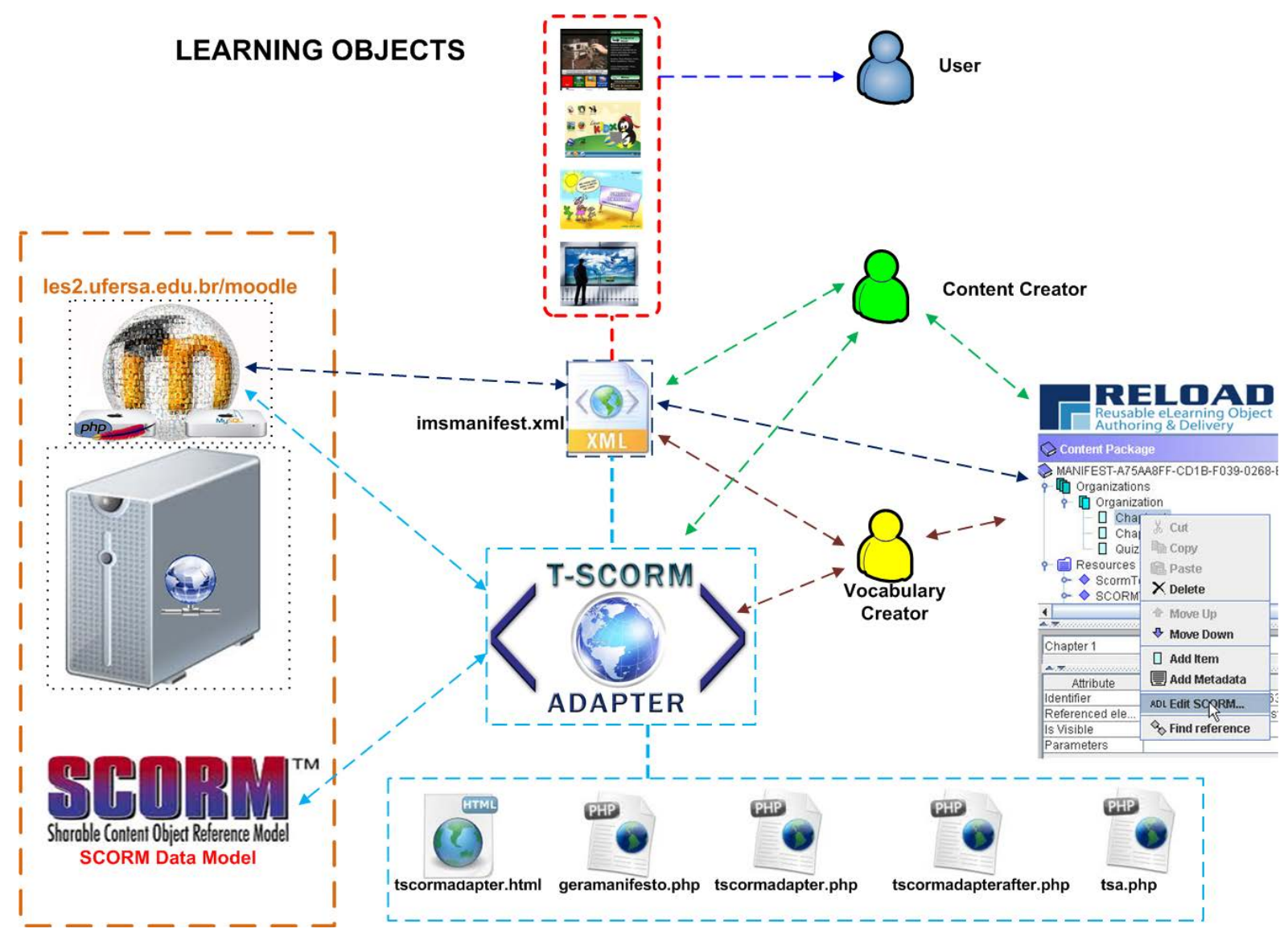

Figure 4. T-SCORM extension architecture. Source: Improved adaptation from (Silva et al., 2012).

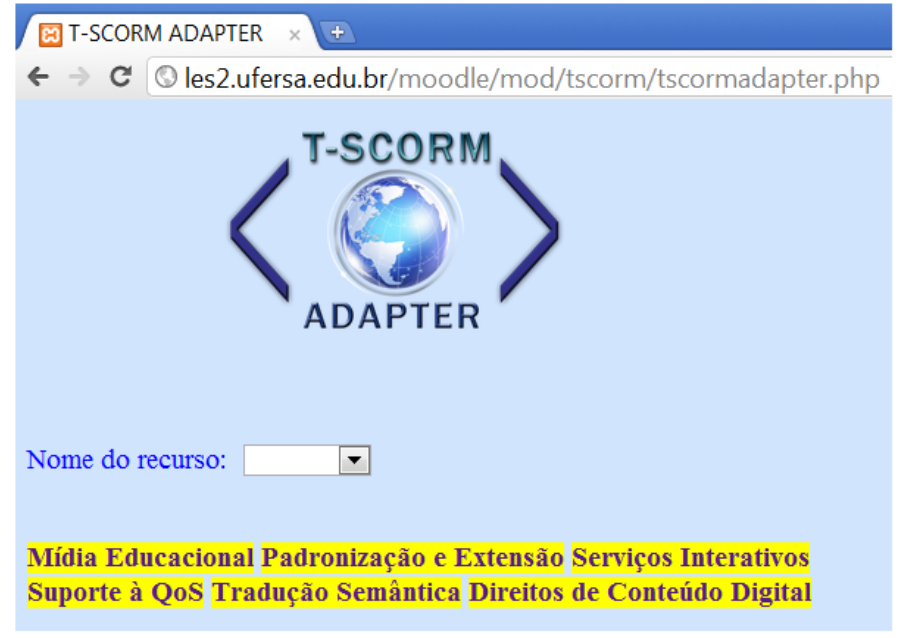

Figure 5. The new T-SCORM ADAPTER.

The T-SCORM ADAPTER was developed in PHP language and integrated with Moodle. In order to make possible to insert the new metadata categories in imsmanifest.xml, was used the XMLDOM (Document Object Model). It is a standard created by $\mathbf{W 3 C ^ { 7 }}$ which is specified as an interface for programming applications, in which allows to work with the structure of documents and the goal is to facilitate access to the elements of a 
document such as tags of an XML file, enabling remove, add or edit its content, attributes and style.

DOM also allows developers to write applications that work properly in all Internet browsers, in addition of Servers on many platforms and even that developers require programming in different languages, the programming model remains.

W3C divided the DOM in different parts (Core, XML, and HTML) and at different levels $(1,2,3)$. DOM is a neutral language, i.e., language-platform independent allowing programs to access the databases and dynamically update the documents content. For this project, we decided to use PHP XMLDOM to load the imsmanifest.xml in order to manipulate it.

Figure 6 shows a user scenario using T-SCORM ADAPTER to modify the imsmanifest.xml and applying just one element of the extension.

In order to apply the T-SCORM extension, we must follow a sequence of four steps. Step 1, you need to create the imsmanifest.xml using Reload Editor. Step 2, rename the file created to imsmanifest_default.xml and places in the root of .../moodle/mod/tscorm/ where Moodle is installed. Step 3, it is chosen the video resource, which is also a LO with metadata to change. Then, you must fill out the information by scrolling the menu tabs. Step 4, click on Enviar button to finish. The information is saved and automatically inserted; also it creates a final copy of imsmanifest.xml that is created separately, but keeping the original organization structure.

In Figure 7, it is shown a part of the PHP code where is started the process that verifies if there is some already created, then it loads the imsmanifest.xml with DOM initiating the search for the videos resources identification in the tags structure of imsmanifest.xml. Once identified, the resources are loaded in the T-SCORM ADAPTER page, in which the user will apply the information on the new metadata elements of these resources separately.

According to Doyle (2009), besides DOM, PHP uses two more methods to analyze grammatically a XML document, which are: XMLParser and SimpleXML. The first is most recommended for XML reading, while

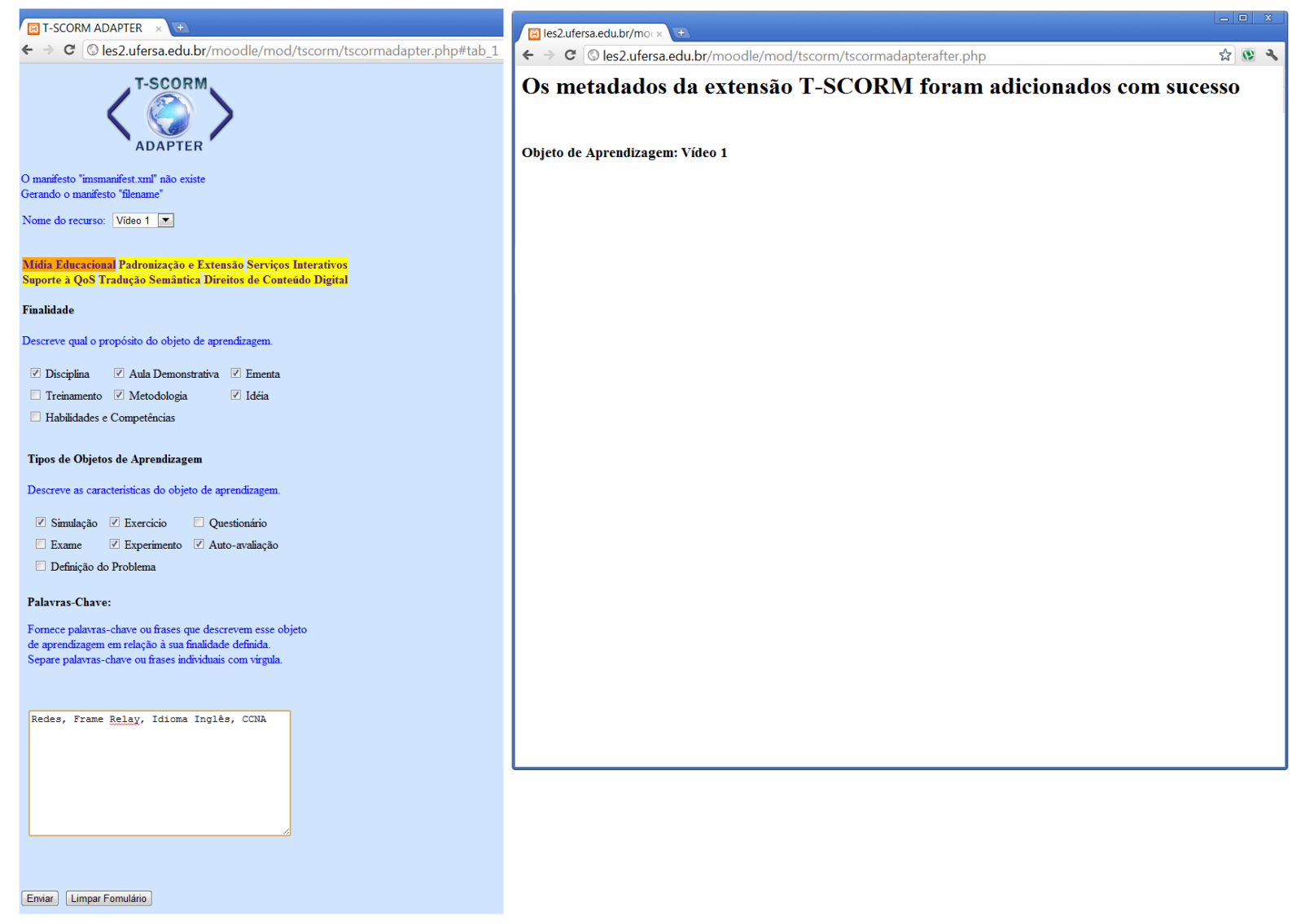

Figure 6. User Scenario of the new T-SCORM ADAPTER. 


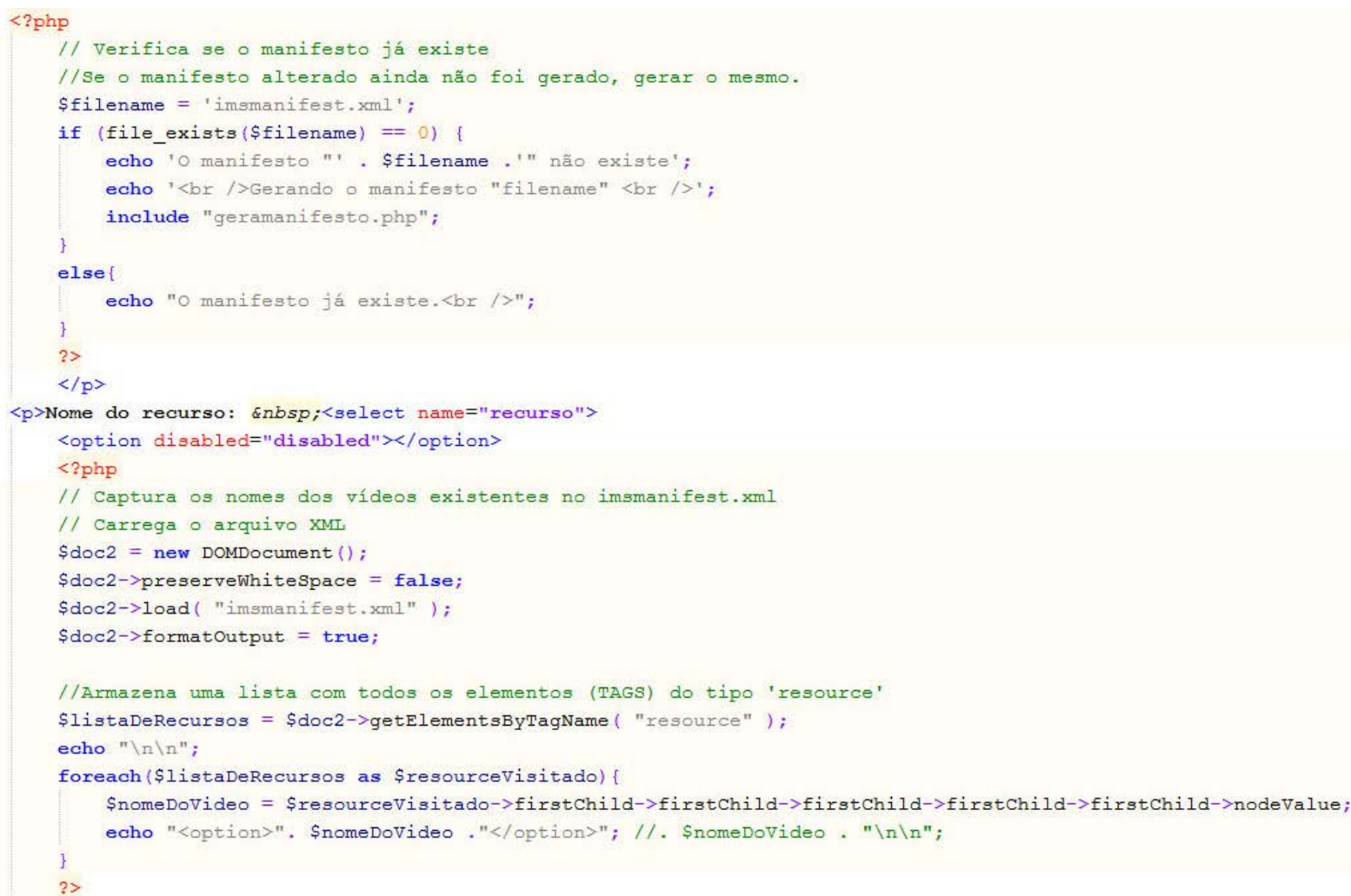

Figure 7. Piece of PHP code using PHP XMLDOM.

the second is based on difficulties found in implementing the XMLDOM by PHP. Despite the Simple XML be considered easier to handle large files, its documentation leaves something to be desired, especially regarding name spaces used to identify elements and attributes of an XML avoiding conflict. It did not have good examples that were useful in our project, and then we did not opt for this approach.

In Figure 8, it is shown the imsmanifest.xml created with the Reload Editor.

In Figure 9, it is shown the imsmanifest.xml after the metadata addition in <educationalmidia $>$ element edited by T-SCORM ADAPTER.

\section{Case Study}

This section describes the technologies and programming languages that were used. In addition of presenting the final results of tests conducted and an analysis of the results found.

\subsection{Recommending Educational Videos for t-Learning Environment}

Yin (2005) defines a case study as an empirical research that investigates a contemporary phenomenon within its real life context, especially when the boundaries between the phenomenon and context are not clearly defined.

Babbie (1999) quoted by (Gomes, 2009) complements that a case study search initially the comprehensive understanding of a single case and knowledge generally applicable in addition to the unique case studied, but by itself, a case study does not guarantee this generalization.

As a part of this work, the T-SCORM-Moodle application was designed to present the final results of the recommending videos process with educational content for iDTV platform. It was developed in NCL (Nested Context Language) and Lua, which is a script language adopted by the middleware Ginga-NCL ${ }^{8}$. The TSCORM-Moodle was created aiming to work integrated with Moodle, which is charge for a large part in the recommending process.

${ }^{8}$ http://www.gingancl.org.br/ 


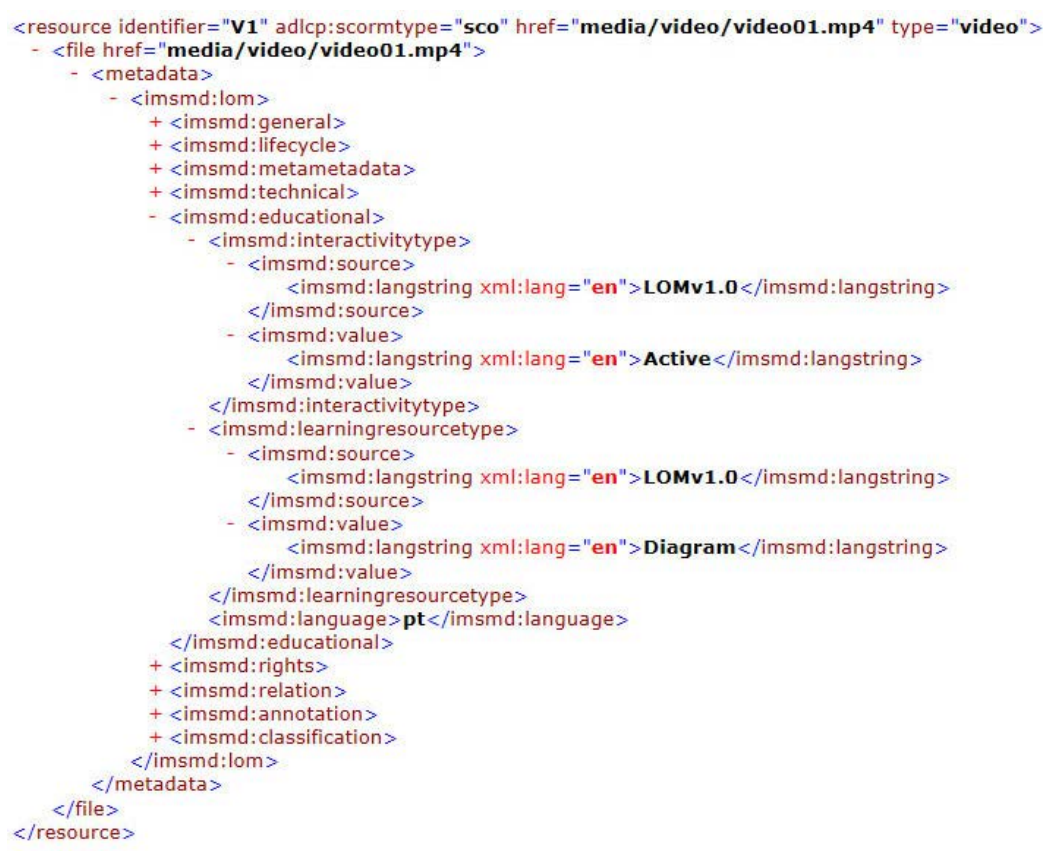

Figure 8. Metadata created with the reload editor.

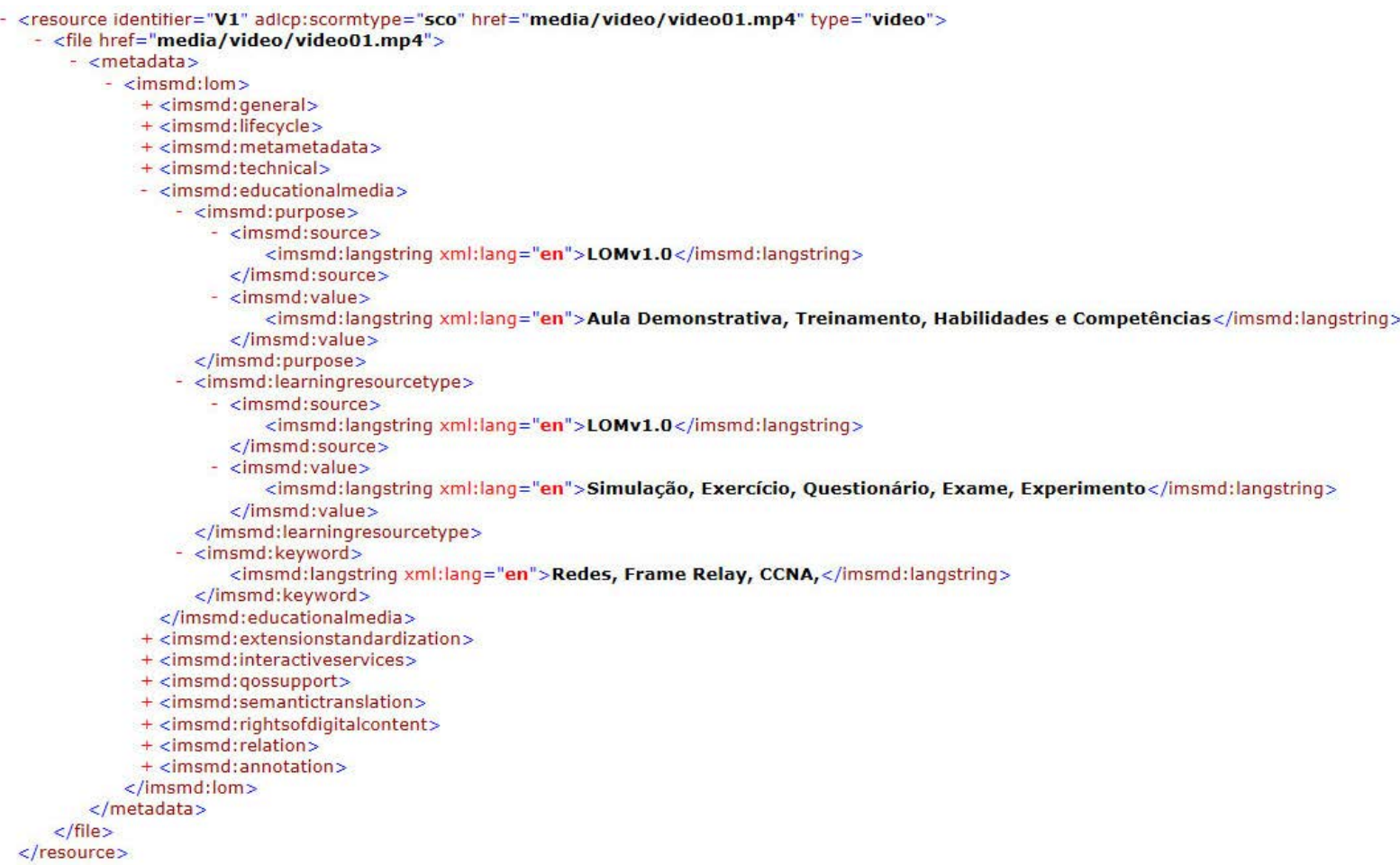

Figure 9. Metadata changed with the new T-SCORM ADAPTER.

A virtual machine such as VMWare ${ }^{9}$ simulates the operation of Ginga-NCL as if it were operating normally in a set-top box. In the prototype created by this work, we have the T-SCORM-Moodle application where will be performed the user authentication process, as well as will be shown the recommendation result of educational videos exclusive to t-Learning environments based on the profile information of the student previously created in Moodle.

$\underline{\text { http://www.vmware.com/ }}$ 
The application stars with a video loop on the home screen (Figure 10). After three seconds, the interactivity icon appears informing that there is an interactive feature ready to be engaged. In this prototype, the interactivity is operated by $<\mathbf{F 1}>$ key on the computer keyboard and makes the application pass to the next screen, which is the one for Login and Password.

In Figure 10, it is shown the home screen of T-SCORM-Moodle.

In Figure 11, it is shown the screen requesting Login and Password of the user.

The creating process of the user profile is done through a form created within the LMS Moodle. For this reason, the Moodle 2.0 version was installed and properly configured with Windows Server 2008 R2 Enterprise, which is physically located at the Software Engineering Laboratory of Federal University of Semi Arid.

In 2012 was created the sub-domain [http://les2.ufersa.edu.br/moodle/] for tests implementation, which made

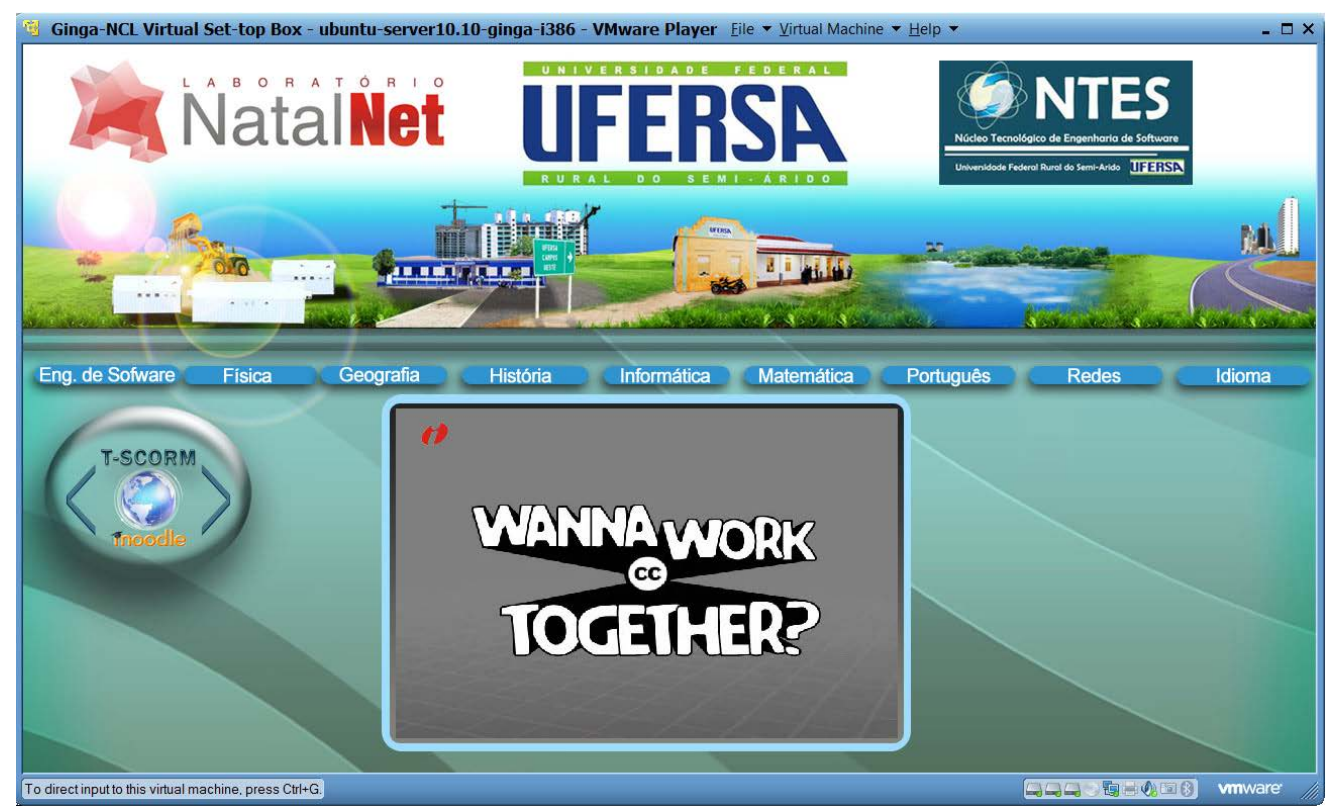

Figure10. Home screen of T-SCORM-Moodle.

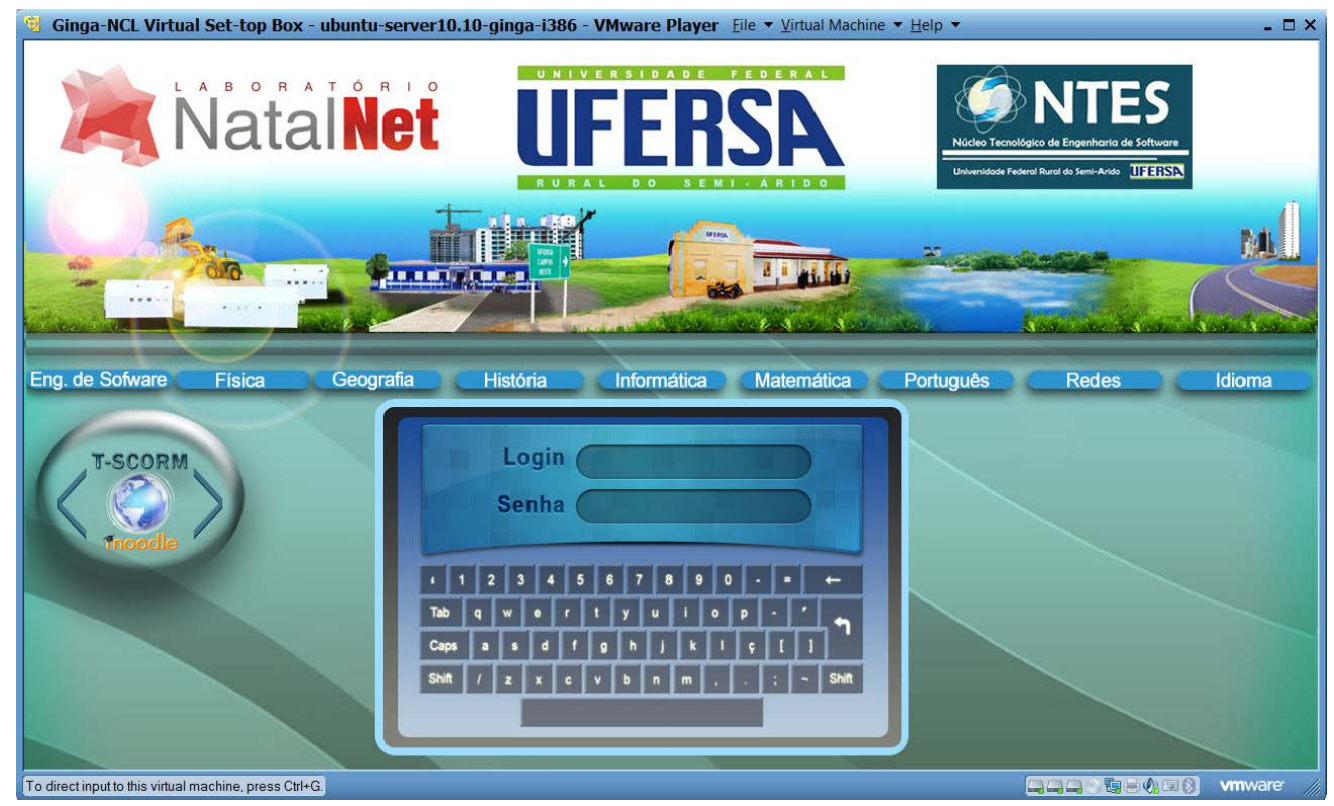

Figure 11. Screen requesting login and password. 
possible the external access in order to perform the tests and get the results, but this sub-domain was discontinued in 2014 since there was an internal problems with this machine. In Figure 12 is shown the Moodle home page.

In Figure 13, it shown the Form T-SCORM-Moodle link, located on top edge left of the screen.

By clicking on the link, the user will be directed to a page which will fill a registry with the information requested on the form as it shown in Figure 14.

In fields of Finalidade, Tipos de Objetos de Aprendizagem, Tipos de Recursos and Disciplinas, the user may choose more than one option. This will ensure that the number of videos in recommendation can be wider. In Figure 15, it is shown the creating process of a user (TESTE). After the filling, click on the Enviar button.

In Figure 16, it is shown the confirmation screen of the registration done successfully.

\subsection{Architecture for Recommending Educational Videos}

Now, it will be presented the architecture that will illustrate and explain how is performed the processes of requesting and recommendation of videos with educational content. The videos are already classified and specified in SCORM standard in the imsmanifest.xml structure with T-SCORM extension properly applied, including the new metadata categories proposed by this work. In Figure 17 is how this process is performed.

The process starts when the T-SCORM-Moodle application sends a HTTP request: with username and password. In client-side with virtual machine, the Lua coding has two functions created: one for sending requisition with login and password and other to receive the response from the server-side as the result of the videos recommendation. In Figure 18 is shown a piece of the Lua code with the request and response functions.

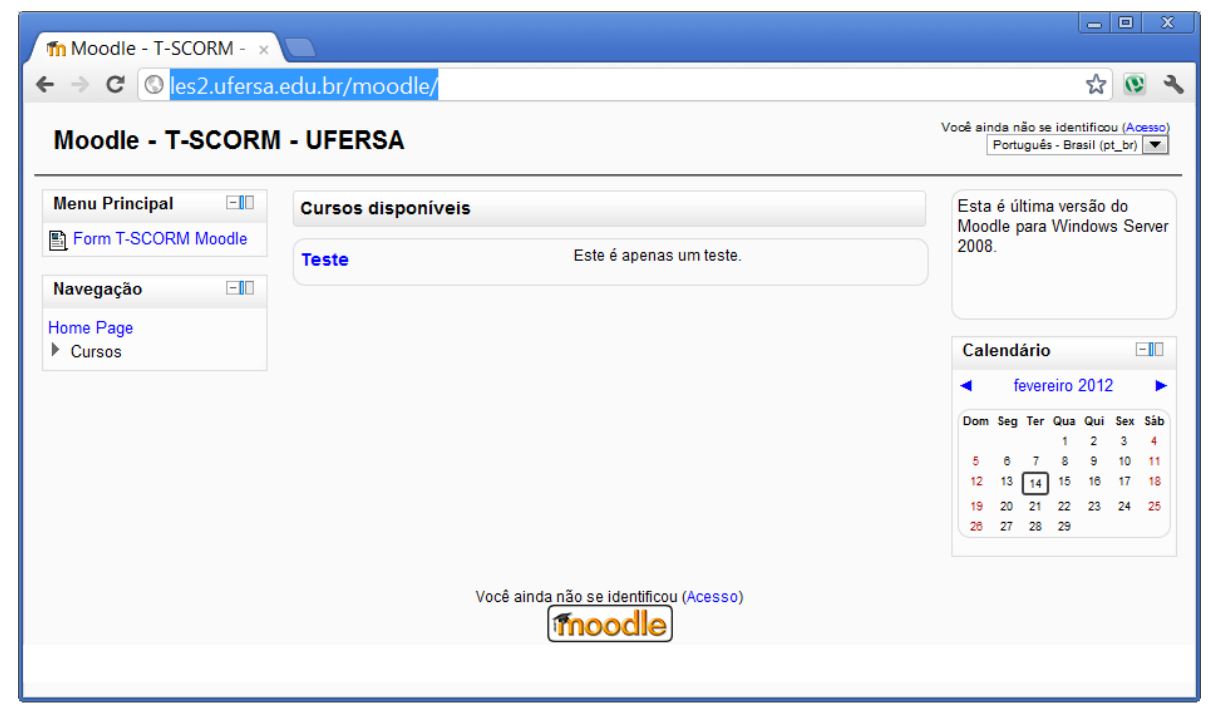

Figure 12. Moodle home page for tests.

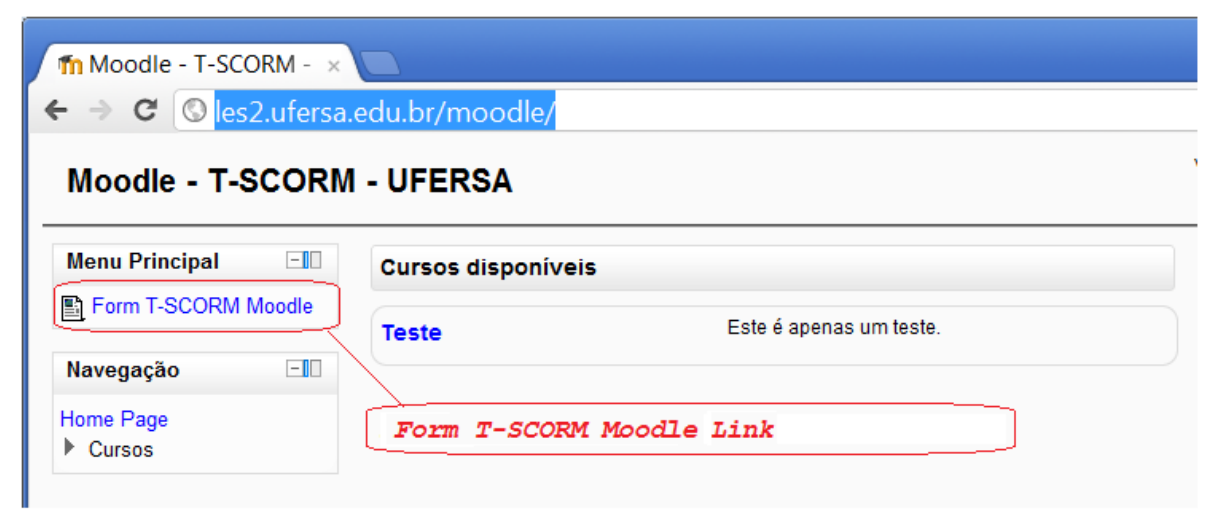

Figure 13. T-SCORM-Moodle link. 


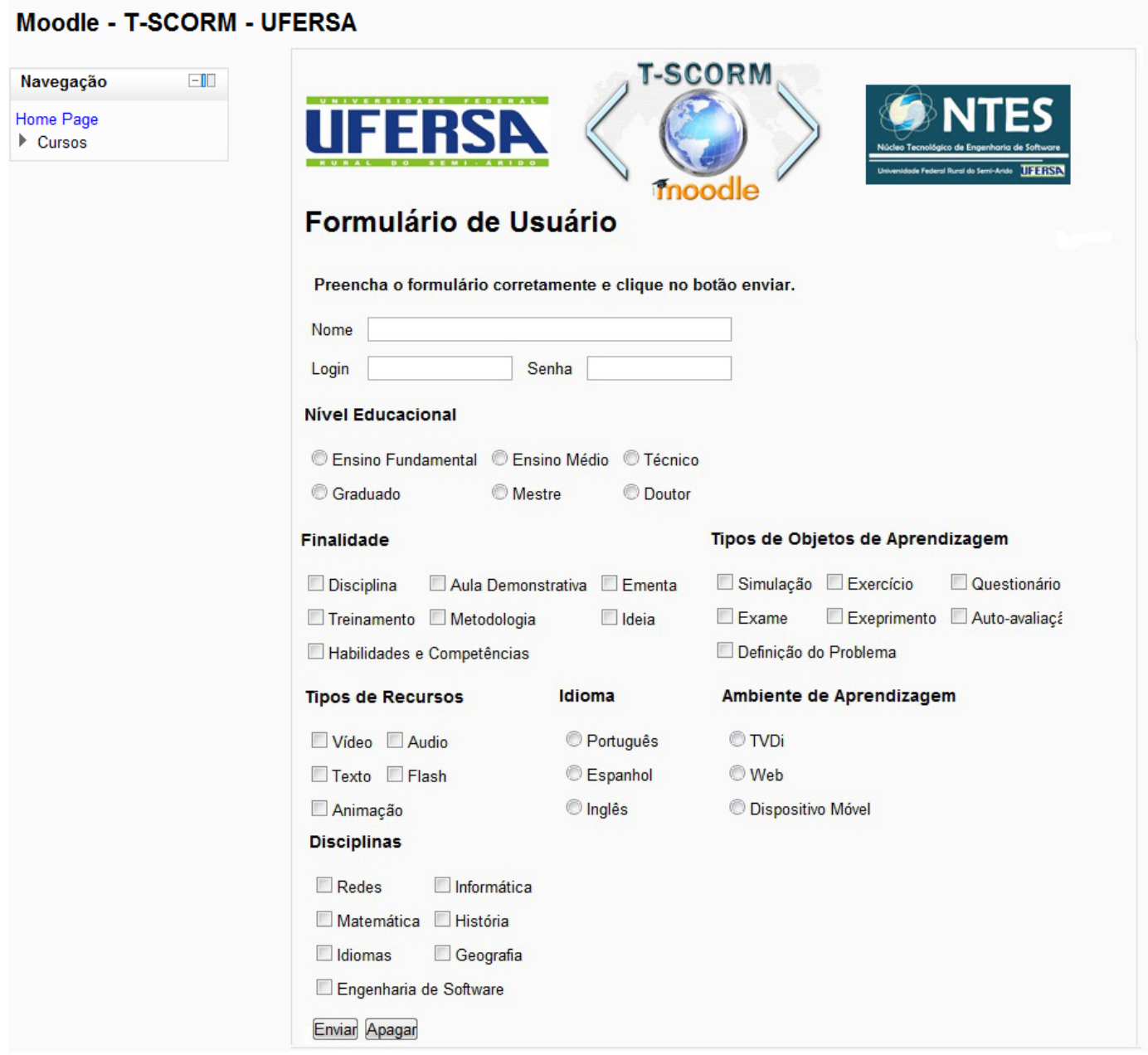

\section{Figure 14. Form T-SCORM-Moodle.}

The process continues when the request reaches the Moodle pointing to the tscorm.php file, and this, in turn, makes the authentication of the login and password in the MySQL Database.

In Figure 19 is shown the piece of code in PHP that performs this task.

Once identified username and password, the process goes ahead, but it is important to remember that the information completed by the user on Form T-SCORM-Moodle are also in MySQL Database. The information are compared with the metadata of the T-SCORM extension applied in the imsmanifest.xml file, which is loaded using the same procedure shown before with the XMLDOM.

In Figure 20 is shown the piece of code in PHP that performs this task.

The next piece of code chosen was from the field FINALIDADE, in order to exemplify how is done the information comparison, having in mind that all fields of category <educationalmedia> are used as recommendation parameters.

At first, the code reads the tag <educationalmedia>, keeps the reading information in a variable named \$finalidadeNoXML, and then, it is checked if any value of this variable is the same as the field FINALIDADE in $M y S Q L$ database where is the variable \$finalidade.

In the event of equality in the information fields, the video resource is recommended and stored in the variable \$recommendation, otherwise, the video resource is not recommended

In Figure 21 is shown how is performed the reading information of the user in the MySQL database with metadata of the category<educationalmedia $>$.

All video resources are visited in the imsmanifest.xml.

In Figure 22 is shown the final part of the code thatshows the values (in this case, the video resources) that 


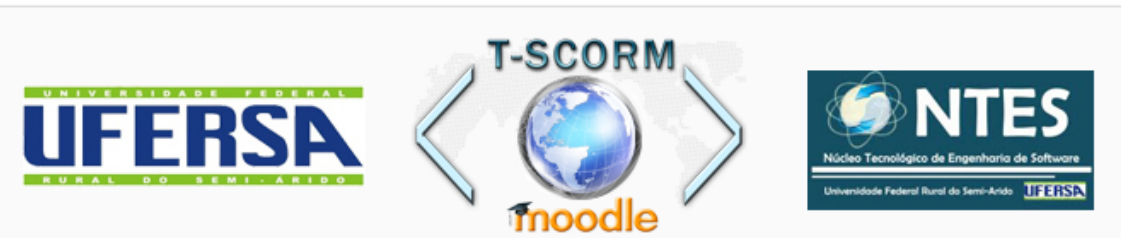

\section{Formulário de Usuário}

Preencha o formulário corretamente e clique no botão enviar.

$\begin{array}{ll}\text { Nome } & \\ \text { LoSTE } & \text { user }\end{array}$

Nível Educacional
Ensino Fundamental
Ensino Médio
Técnico
Graduado
(9) Mestre
Doutor

Finalidade

$\begin{array}{ll}\nabla \text { Disciplina } & \checkmark \text { Aula Demonstrativa } \\ \square \text { Treinamento } & \square \text { Metodologia }\end{array}$

$\checkmark$ Habilidades e Competências

Tipos de Recursos
$\square$ Vídeo $\square$ Audio
$\square$ Texto $\square$ Flash
$\square$ Animação

Idioma

(9) Português

Espanhol

Inglês
Tipos de Objetos de Aprendizagem
$\checkmark$ Simulação $\nabla$ Exercício $\square$ Questionário
$\square$ Exame $\quad \square$ Exeprimento $\square$ Auto-avaliação
$\checkmark$ Definição do Problema

Ambiente de Aprendizagem

(6) TVDi

Web

Dispositivo Móvel

Disciplinas

$$
\begin{aligned}
& \checkmark \text { Redes } \quad \square \text { Informática } \\
& \checkmark \text { Matemática } \quad \square \text { História } \\
& \square \text { Idiomas } \quad \square \text { Geografia } \\
& \square \text { Engenharia de Software }
\end{aligned}
$$

Enviar Apagar

Figure 15. Creating a user (TESTE).

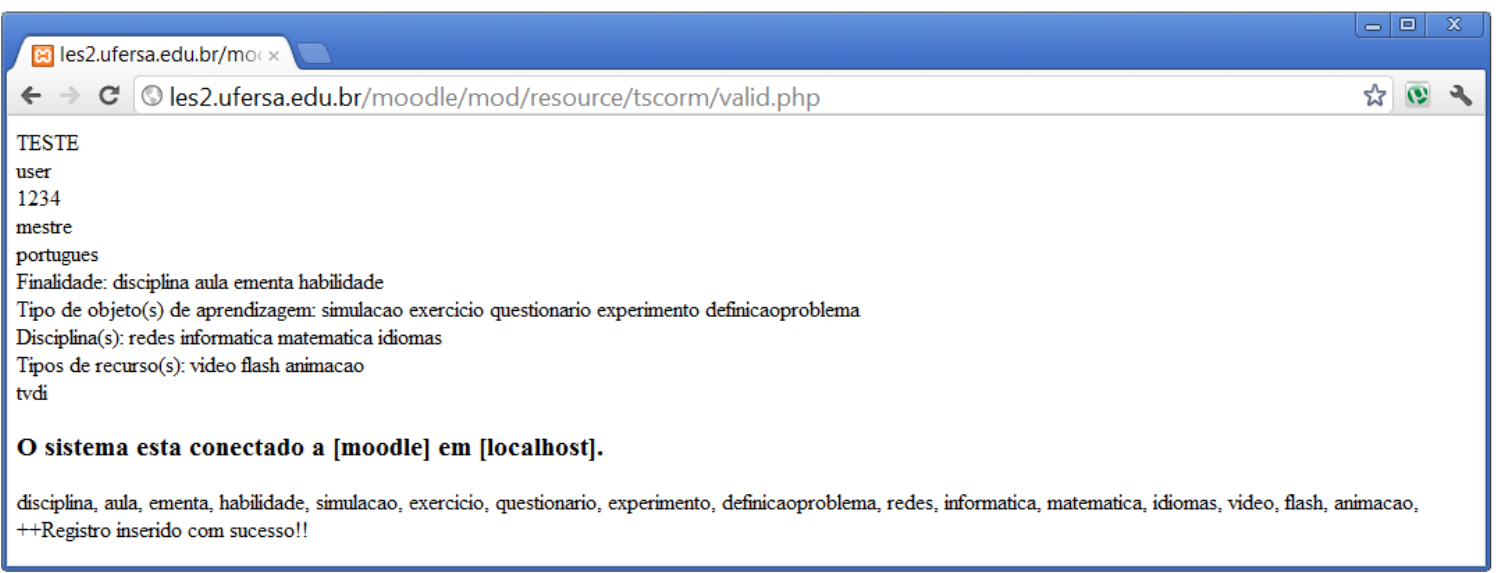

Figure 16. Confirmation screen. 


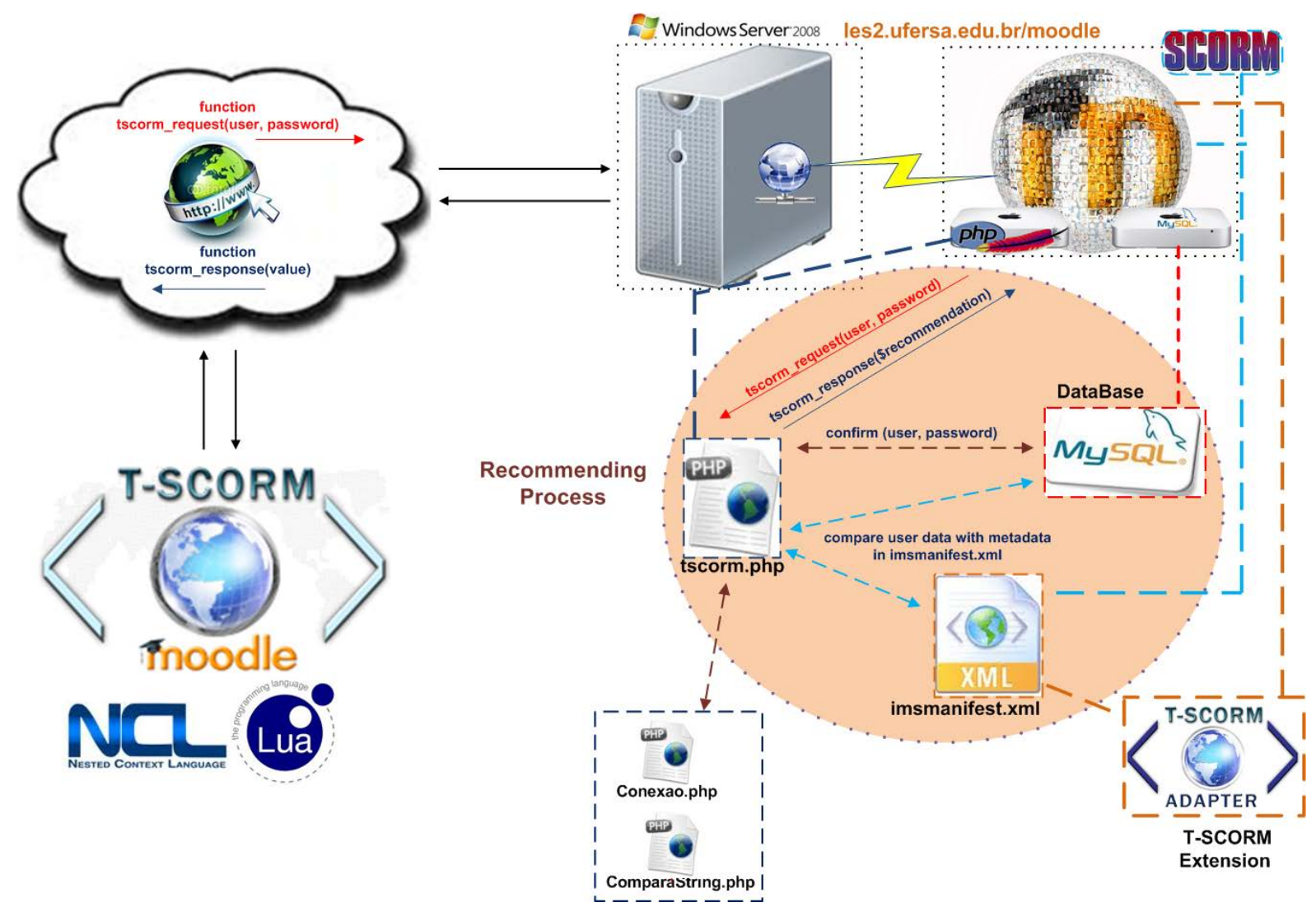

Figure 17. Architecture for recommendation process.

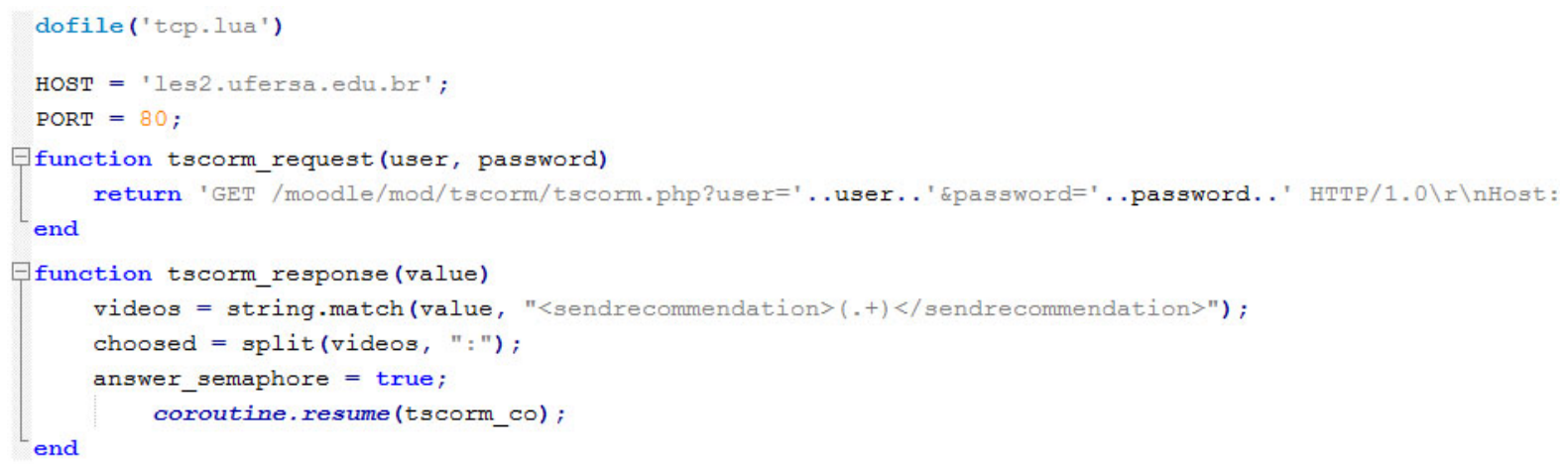

Figure 18. Request function code.

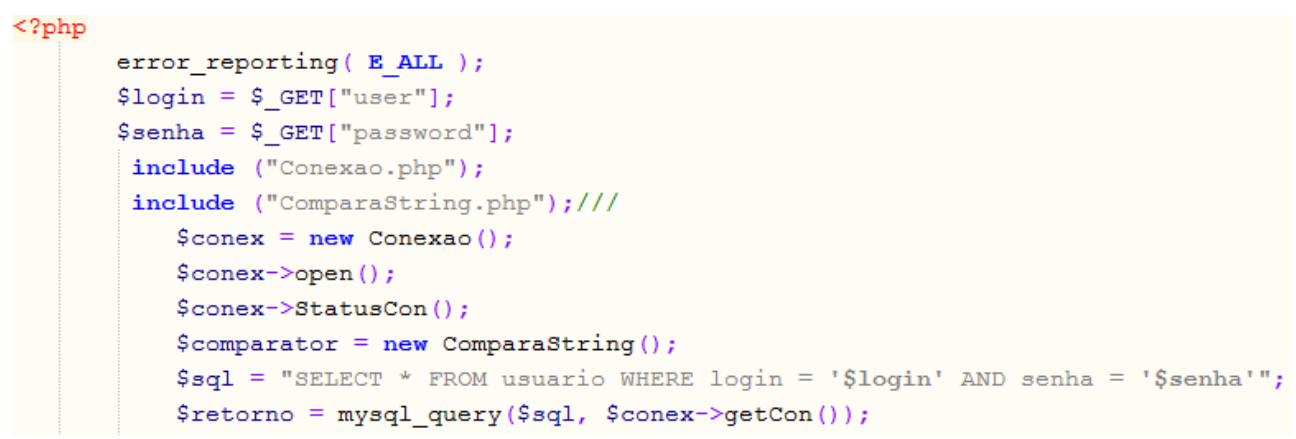

Figure 19. Code for username and password authentication. 


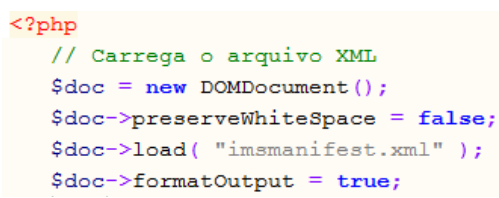

Figure 20. Code for load the imsmanifest.xml file.

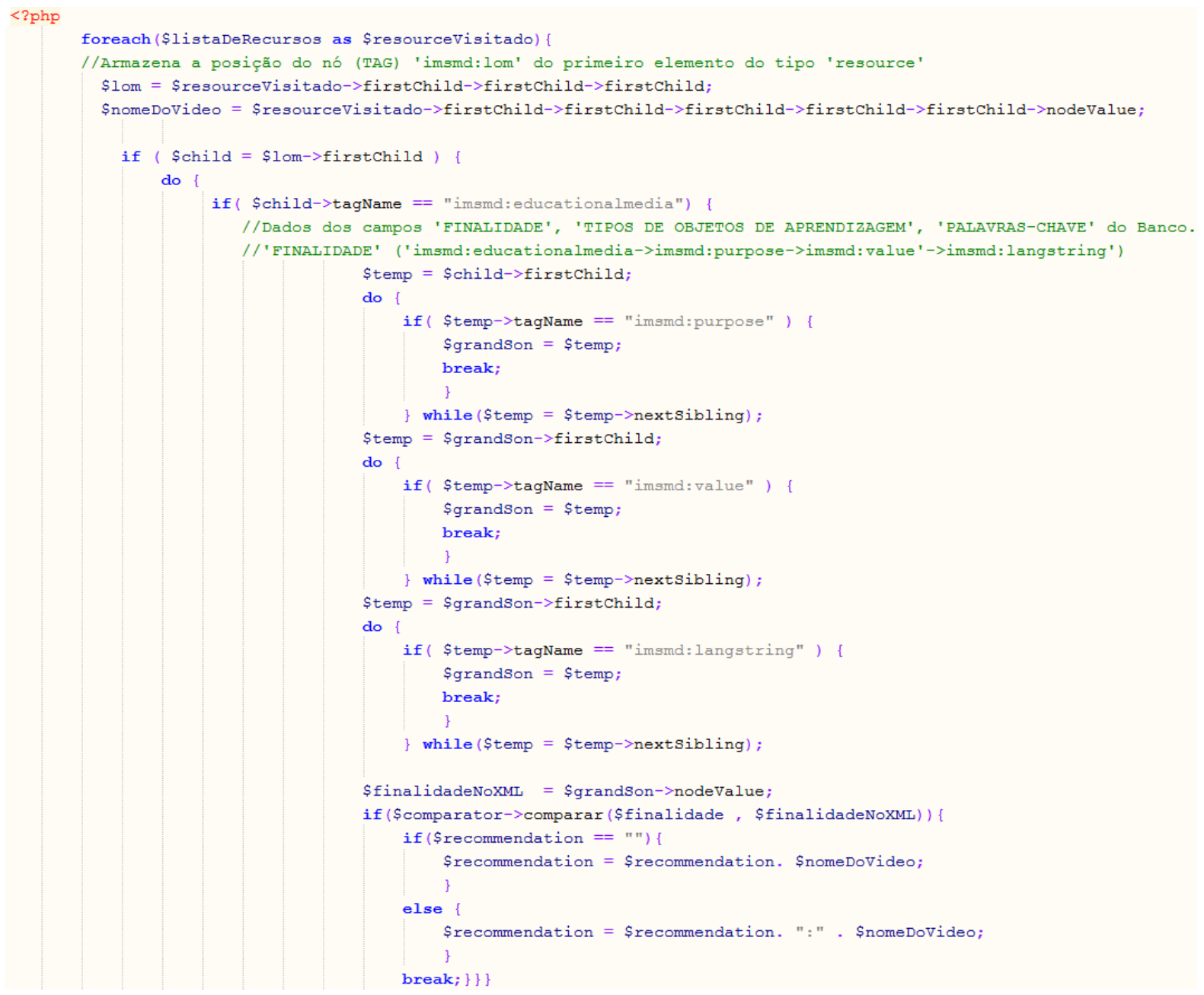

Figure 21. Code for LOs recommendation.

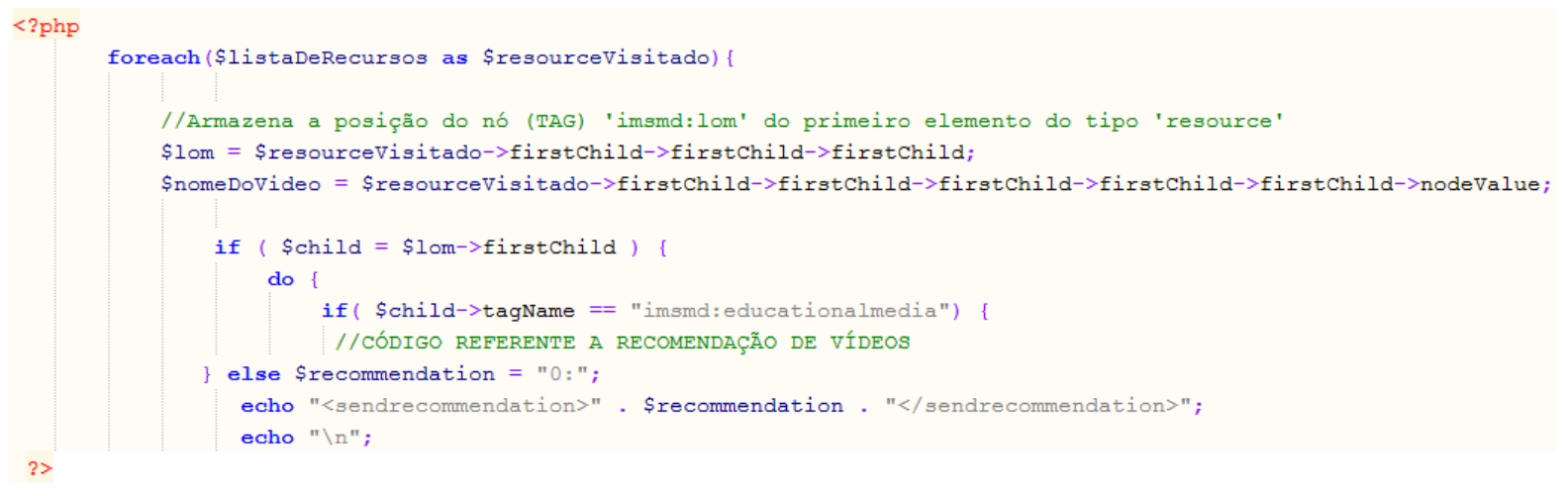

Figure 22. Code for LOs recommendation. 
are sent in the variable \$recommendation for a recommendation, or not, of videos. Having in mind that there was a comment in this part before, where there was the piece of code of the recommendation (see Figure 22).

\subsection{Tests and Results}

For testing and validation of the T-SCORM extension in this work, three users have created their profiles in order to test the recommending process according to their profile features.

In Figure 23 is shown the users that are registered in the Moodle database in the table usuario.

Using a virtual machine with the middleware Ginga-NCL (see Figure 24), we used T-SCORM-Moodle application (see Figure 25) to perform tests with three users.

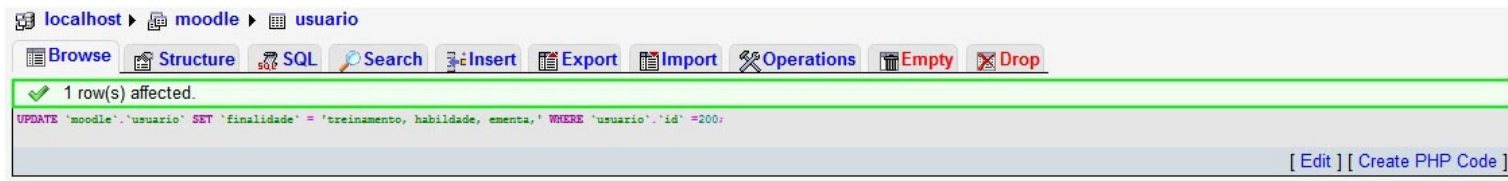

\begin{tabular}{|c|c|}
\hline \multicolumn{2}{|c|}{ Showing rows $0-4\left(\sim 5^{1}\right.$ total, Query took $\left.0.0005 \mathrm{sec}\right)$} \\
\hline $\begin{array}{l}\text { SELBCT * } \\
\text { FBMM "uguario } \\
\text { LMITIT } 0,30\end{array}$ & \\
\hline & $Г$ Profiling [ Edit ] [ Explain SQL ] [ Create PHP Code ] [ Refresh ] \\
\hline
\end{tabular}

\begin{tabular}{|c|c|c|c|c|c|c|c|c|c|c|c|c|c|}
\hline & & & Show: & 30 & $\operatorname{row}(s)$ & starting $\mathrm{fr}$ & om record $\# 0$ & & & & & & \\
\hline & $n \longdiv { \text { ho } }$ & rizon & & & $\nabla$ & mode and & repeat headers after 100 & cells & & & & & \\
\hline $\begin{array}{l}\text { Sort b } \\
+ \text { Opt }\end{array}$ & $\begin{array}{l}\text { y key } \\
\text { ions }\end{array}$ & $\mathrm{No}$ & & & 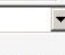 & & & & & & & & \\
\hline & $-\mathrm{T}-$ & & nome & id & login & senha & finalidade & toaprend & neduc & idiomas & disciplinas & trecursos & ambiente \\
\hline$\Gamma$ & 8 & $x$ & carlos & 199 & carlos & 1234 & disciplina, habilidade, & simulacao, exercicio, & mestre & portugues & $\begin{array}{l}\text { redes, informatica, } \\
\text { matematica, }\end{array}$ & video, audio, & tvdi \\
\hline$\Gamma$ & 8 & $x$ & miguel & 200 & miguel & 1234 & $\begin{array}{l}\text { treinamento, } \\
\text { habildade, ementa, }\end{array}$ & simulacao, ideia, exercicio, & mestre & portugues & redes, informatica, & animacao, & tvdi \\
\hline$\Gamma$ & 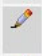 & X & diogo & 201 & diogo & 1234 & treinamento, & exercicio, questionario, & mestre & portugues & $\begin{array}{l}\text { informatica, engenharia } \\
\text { de software, }\end{array}$ & video, flash, & tvdi \\
\hline$\Gamma$ & 8 & $x$ & TESTE & 202 & user & 1234 & $\begin{array}{l}\text { disciplina, aula, } \\
\text { ementa, habilidade, }\end{array}$ & $\begin{array}{l}\text { simulacao, exercicio, } \\
\text { questionario, experimento, d... }\end{array}$ & mestre & portugues & $\begin{array}{l}\text { redes, informatica, } \\
\text { matematica, idiomas, }\end{array}$ & $\begin{array}{l}\text { video, flash, } \\
\text { animacao, }\end{array}$ & tvdi \\
\hline
\end{tabular}

Figure 23. Users registered in the database for tests.

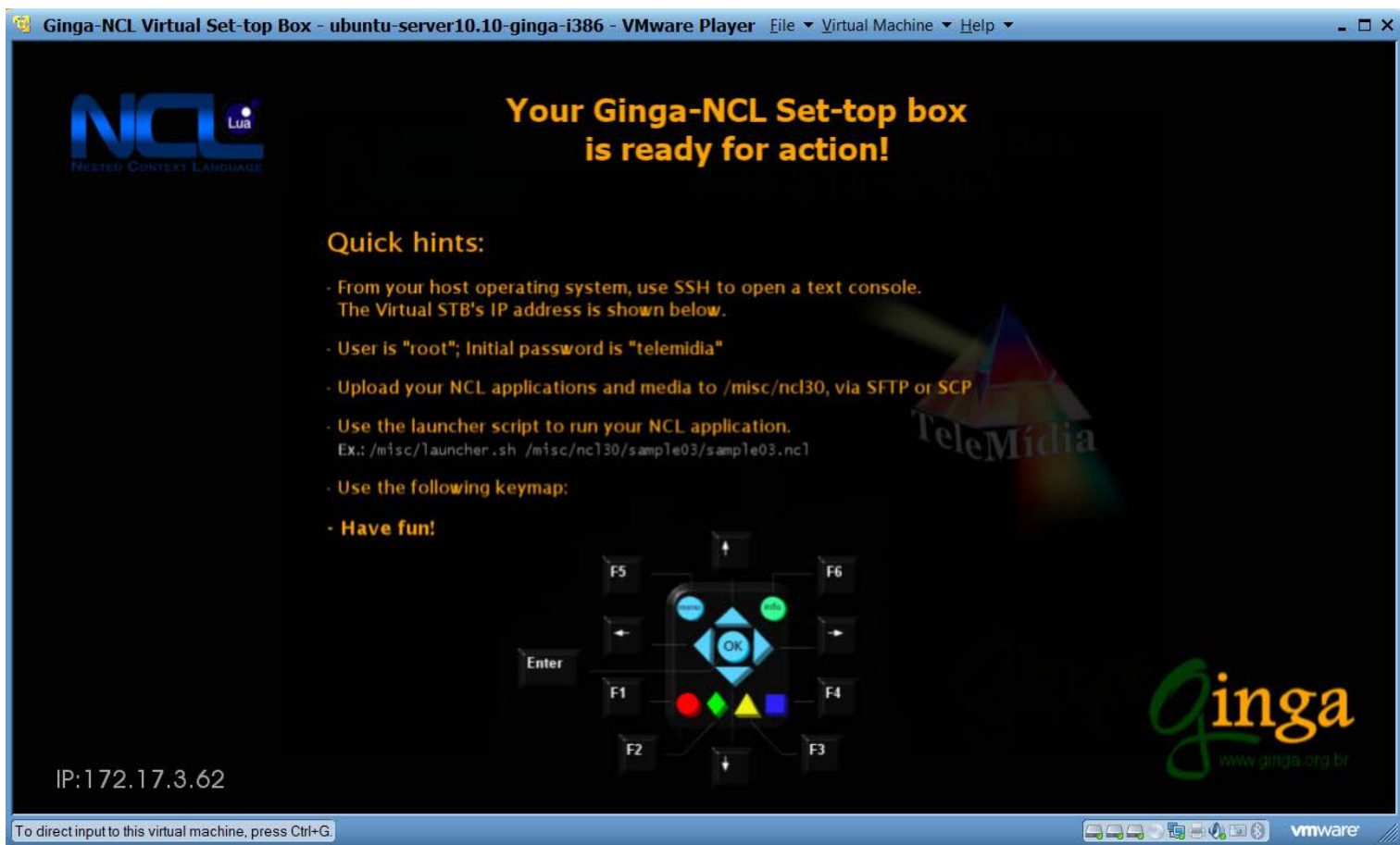

Figure 24. Virtual machine with Ginga-NCL. 


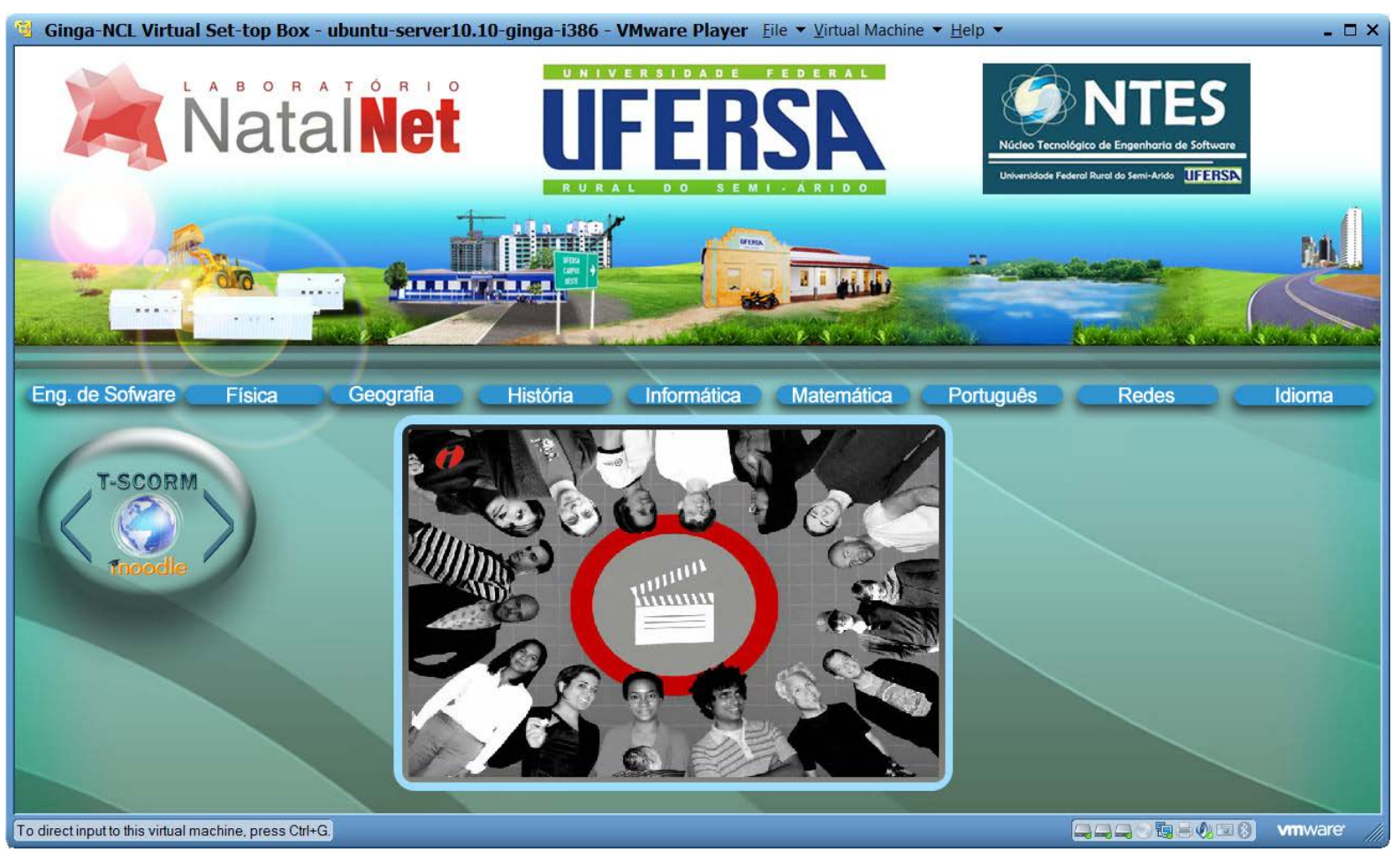

Figure 25. Virtual machine with T-SCORM moodle.

In Figure 24 is shown the Virtual Machine with Ginga-NCL.

In Figure 25 is shown the Virtual Machine with T-SCORM Moodle.

Below are shown screens requiring login and password and the recommendation results for three users: Carlos, Miguel and Diogo. In Figure 26 is shown the recommendation result for the user Carlos.

In the recommendation result for the user Carlos, were compared information that are in the $M y S Q L$ database in the table usuario with information of the tag <educationalmedia> of imsmanifest.xml file.

The field Finalidade of T-SCORM ADAPTER tool (see Figure 7) corresponds to the node <imsmd:purpose $>$ (see Figure 9) of the tag <educationalmedia $>$. The value of this tag is compared with the field finalidade (see Figure 23) of the table usuario.

Similarly, the value of node <imsmd:learningresourcetype>, which would be the field Tipos de Objetos de Aprendizagem is compared with the field toaprend. Finally, the field Palavras-Chave, which stores values in the node <imsmd:keyword $>$ is compared with the remaining fields neduc, idiomas, disciplinas, trecursos, and ambiente.

Once done the recommendation, some videos in the repository were recommended to user Carlos, such: RedesI, Redes II, Redes III, Química, Física, Geografia, História, MatemáticaandMatemática II.

It is possible that not all videos are of total interest for viewing, but analyzing the information in the database, it is likely that videos such as Geografia and História have been recommended because they have in the node <imsmd:learningresourcetype> values such as simulação and exercício in the imsmanifest.xml, which not necessarily makes it an interesting video for a user with a computing profile. In this case, the video would not be viewed by the user, unless he may be interested.

The same process is repeated for the next two results of users Miguel and Diogo. In Figure 27 is shown the recommendation result for the user Miguel.

In the recommendation result for user Miguel, the videos recommended in the repository were: RedesI, Redes II, Redes III, Engenharia de Software, Engenharia de Software II, Química, Física, Geografia and História. This result seems a little with the recommendation made previously for user Carlos.

However, videos such as Matemática and Matemática II were not recommended.

In Figure 28 is shown the recommendation result for the user Diogo.

In the recommendation result for user Diogo, only the videos Redes and Redes II were recommended. It is 

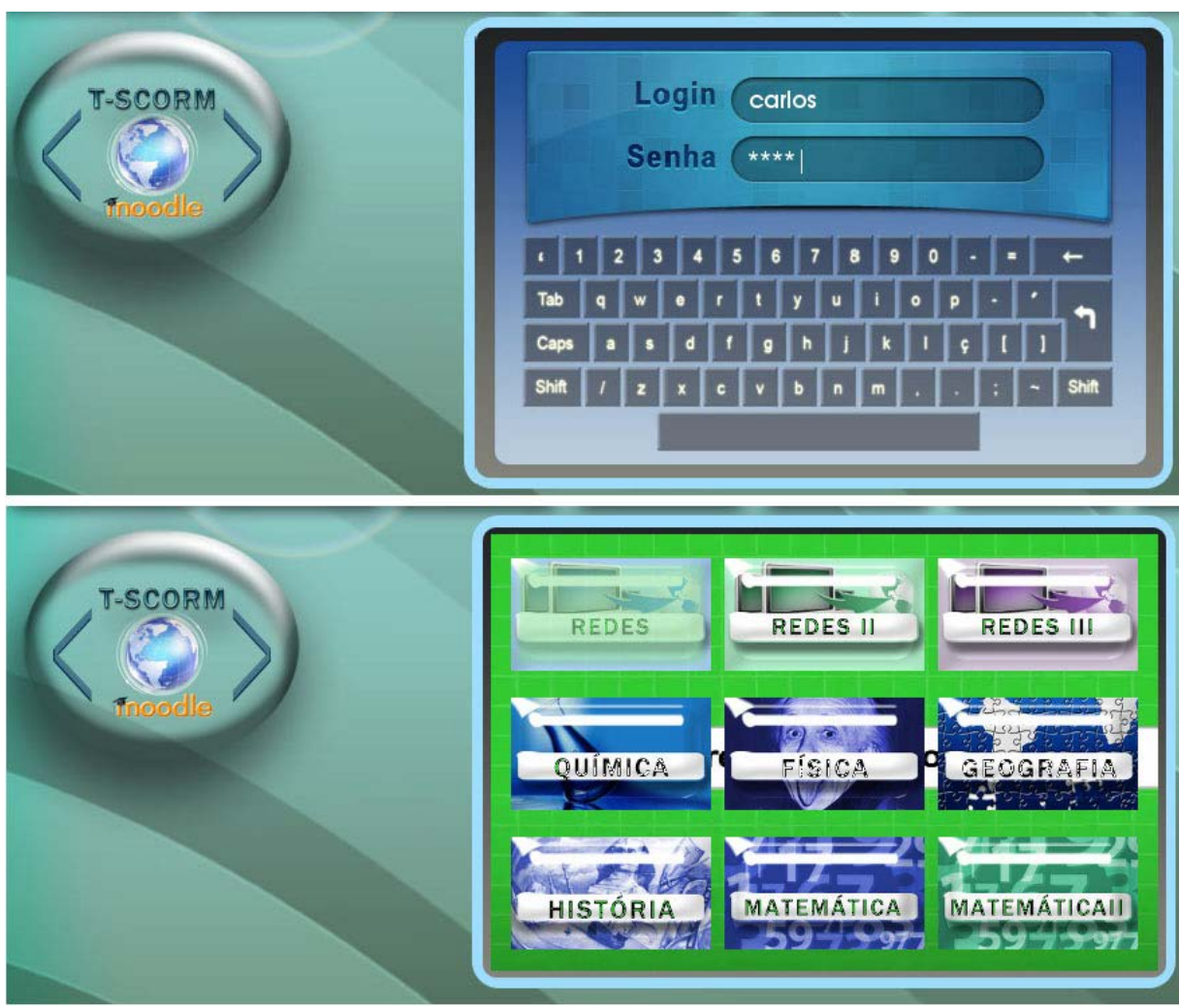

Figure 26. Recommendation result for a user (Carlos).

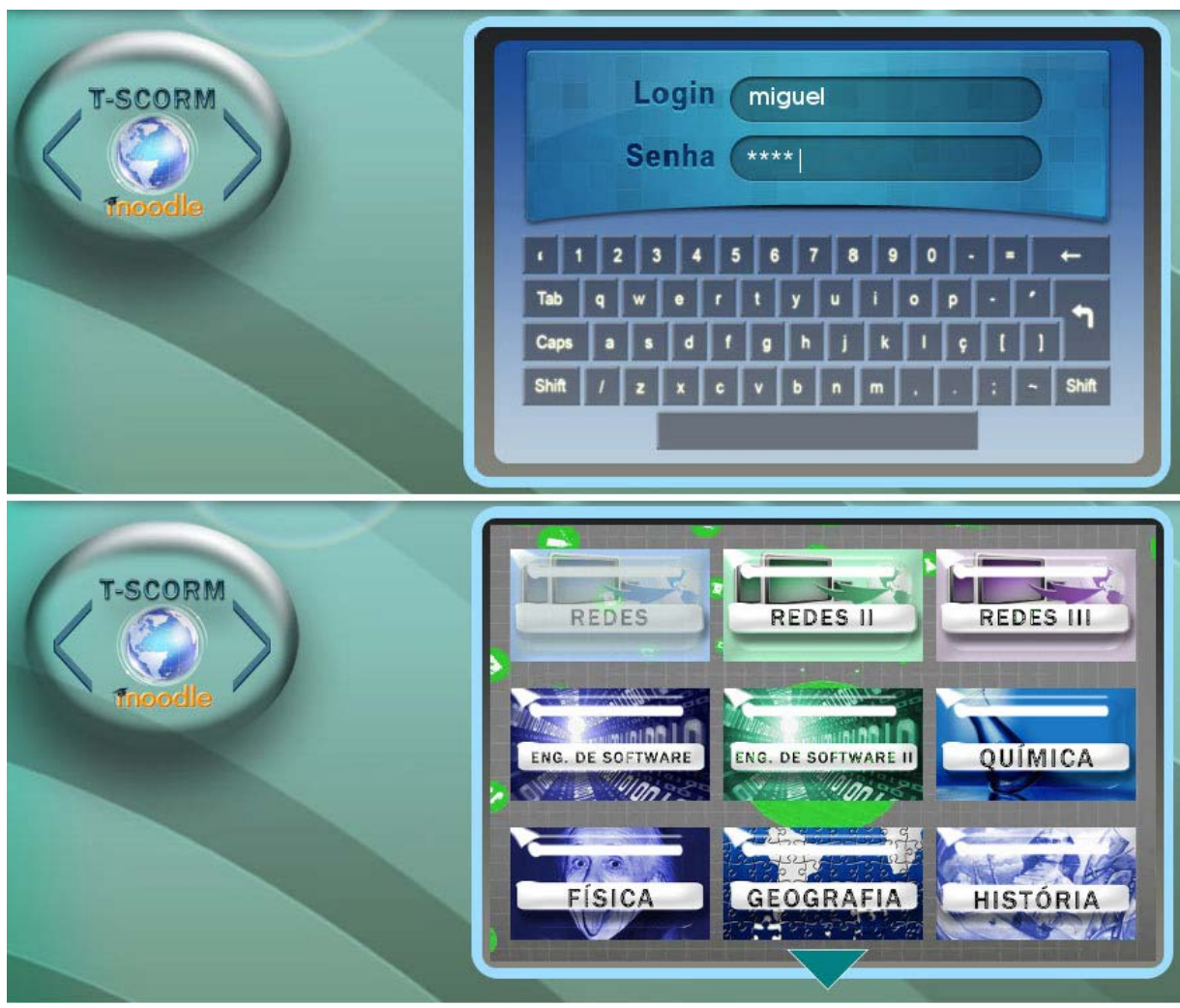

Figure 27. Recommendation result for a user (Miguel). 


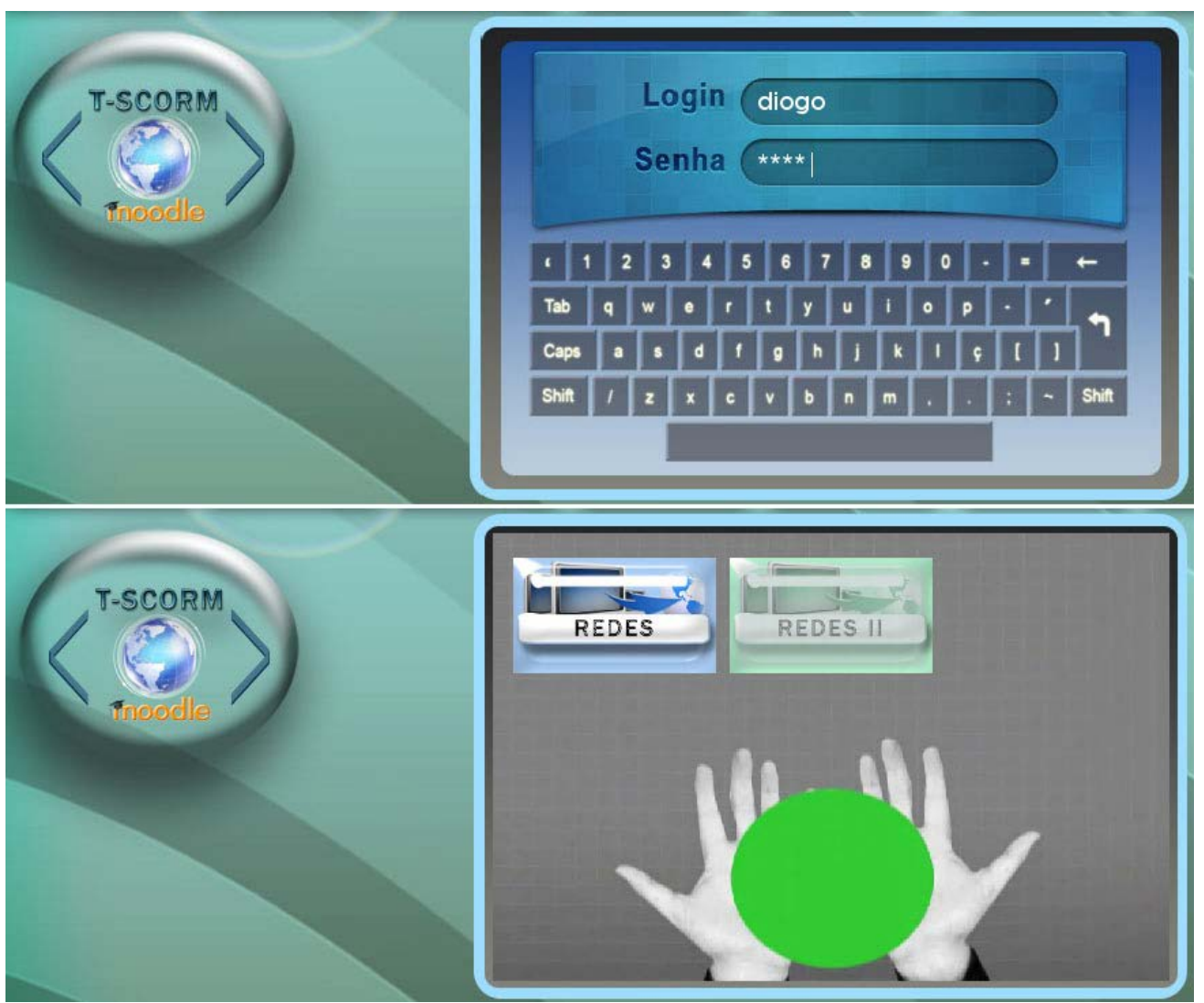

Figure 28. Recommendation result for a user (Diogo).

possible to notice in database that only objects with the purpose of treinamento would be chosen, and this has reduced the options for videos recommendation, which in this case, were only two.

\subsection{Analysis of the Results and Conclusions}

According to Bates (2003) quoted by (Gomes, 2009), in order to develop a strategy of great range and especially in educational scope, the governments must include the iDTV in this process. In the same way, they should also develop wider strategies for Distance Education considering many solutions offered in the t-Learning area.

The TV has now become a tool which can offer many learning opportunities. Using it in the Distance Education area, the learning can be accomplished in your own residence, which becomes an important factor since many people prefer study at home. Some factors such as the high evasion rate, the precariousness of some public schools and the difficulty of the student in learning content, make the iDTV a fundamental mechanism to entertain, inform and educate the students.

What could be expected in medium term is that the iDTV may increasingly offer possibilities that go beyond the classroom and the means of formal education already known. Taking into account the fact that the TV is a means of communication very integrated with the popular culture, it has a great influence on the population, as well as generates a high expectation in regarding to the quality when using the service.

According to the observations done during the tests and analyzing the results, it has been seen that the users that had more information related to the choice options in their profiles had an incidence of videos recommendation increased. That is, the less options and preferences the user has, the lower will be the recommendation.

The results lead to the conclusion that the proposal of the T-SCORM extension was considered productive, at the moment that the purpose of this work is to improve the specification and classification of LOs with educational content regarding to their metadata information compared to the user cognitive information for iDTV. This made the navigation and search processes by LOs in the recommending process become much more efficient and fast. 


\subsection{Related Work}

In (Rey-Lopez et al., 2009), it is proposed an adaptation in the Shareable Content Object (SCO) ${ }^{10}$. In the proposed extension, new elements have been introduced in the data model, allowing the objects can request to the LMS information about the user's characteristics and thus, show the content in accordance with such information. At the activity level, new sequencing rules have been created, and making the presented structure to the users depends on their cognitive status and preferences. The information about these adaptation parameters are obtained starting from a user profile, using inference rules. As a result, courses created are obtained with the purpose of be personalized before make them available to the user. Figure 29 shows the target scenario.

The focus of our work is different, considering the fact that we are proposing an extension of the SCORM standard directly in the metadata of LOM standard, improving the support to educational content through a detailed specification in how the LOs could be better delivered on the iDTV platform.

Simoes, Luis, \& Horta (2004) introduce a proposal for an extension of the SCORM standard, which allows the modeling of a course related to the entities that surround the LOs and the aggregation content. It is suggested the creation of a new category Environmental in the LOM standard in parallel with the current categories.

Table 1 shows the recursive hierarchy proposed by the authors. The fields for the data may be related to describe, in an arbitrary manner, complex structures that represent modeled entities.

In Figure 30 is shown a recursive item in the application and its pseudocode.

The extension presented in (Simoes, Luis, \& Horta, 2004) has similarity with the extension proposed in this paper regarding to proposing changes in the structure of the LOM standard. However, our proposal is to create more elements in order to better support the educational content contained in LOs for iDTV.

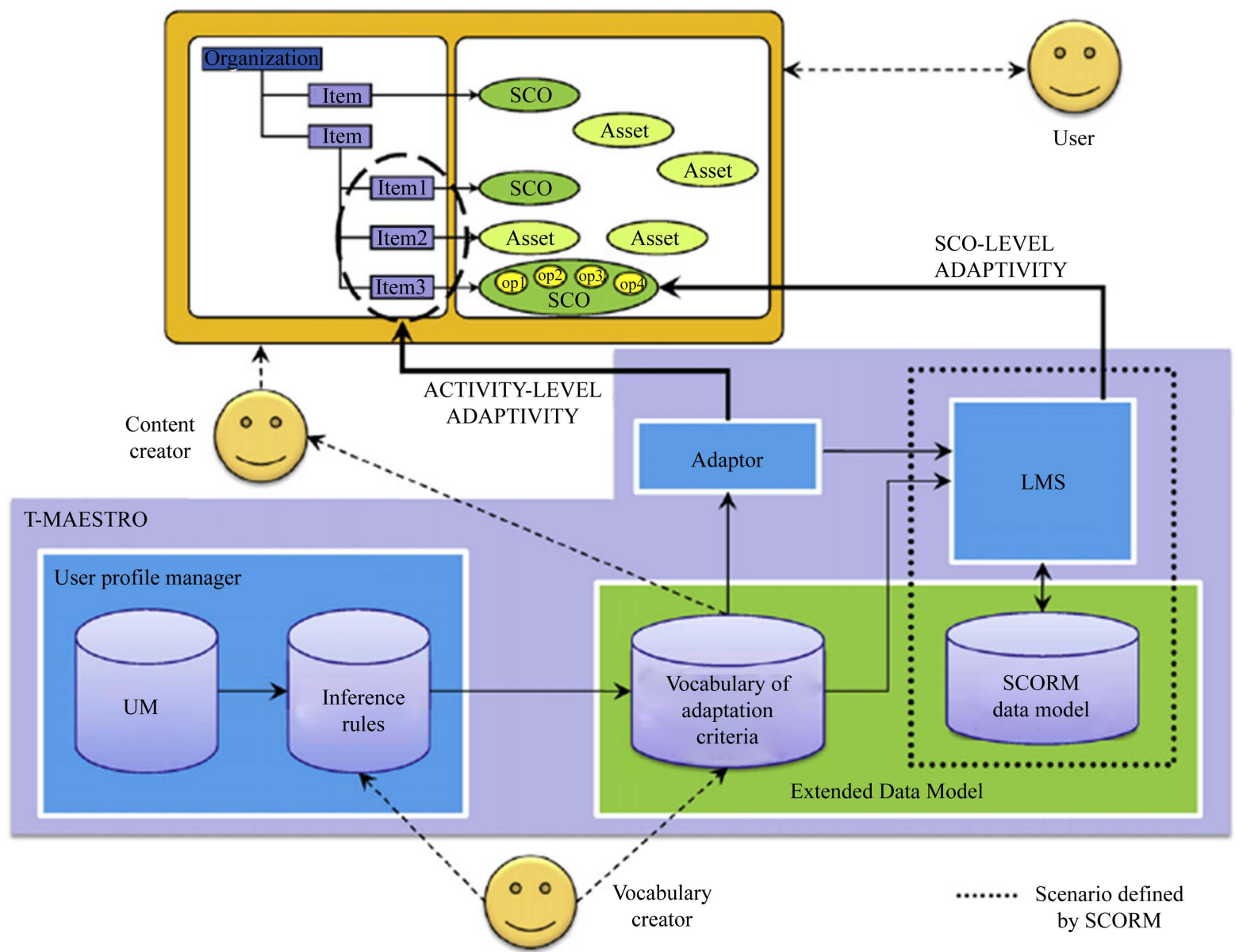

Figure 29. Target scenario. Source: (Rey-Lopez et al., 2009).

${ }^{10}$ Functional component of SCORM. 
Table 1. Extension category. Source: Adapted from (Simoes, Luis, \& Horta, 2004).

\begin{tabular}{|c|c|c|c|c|}
\hline $\mathrm{Nr}$ & Name & Description & Multiplicity & Type \\
\hline 10 & Environmental & $\begin{array}{l}\text { This category models the environment where aggregation is inserted in. It } \\
\text { describes the course entities that are related with learning contents. }\end{array}$ & 0 or 1 & Container \\
\hline 10.1 & Item & Entity in the content aggregation environment. & 1 or more & Container \\
\hline 10.1 .1 & Type & Entity type. & 1 & Vocabulary \\
\hline 10.1 .2 & Value & Entity content or value. & 0 or 1 & LangString \\
\hline 10.1 .3 & Metadata & Metadata describing this entity. & 0 or 1 & Container \\
\hline 10.1 .4 & Item & Sub-entity. The structure of this element is represented the as 10.1 item & 0 or more & Container \\
\hline
\end{tabular}
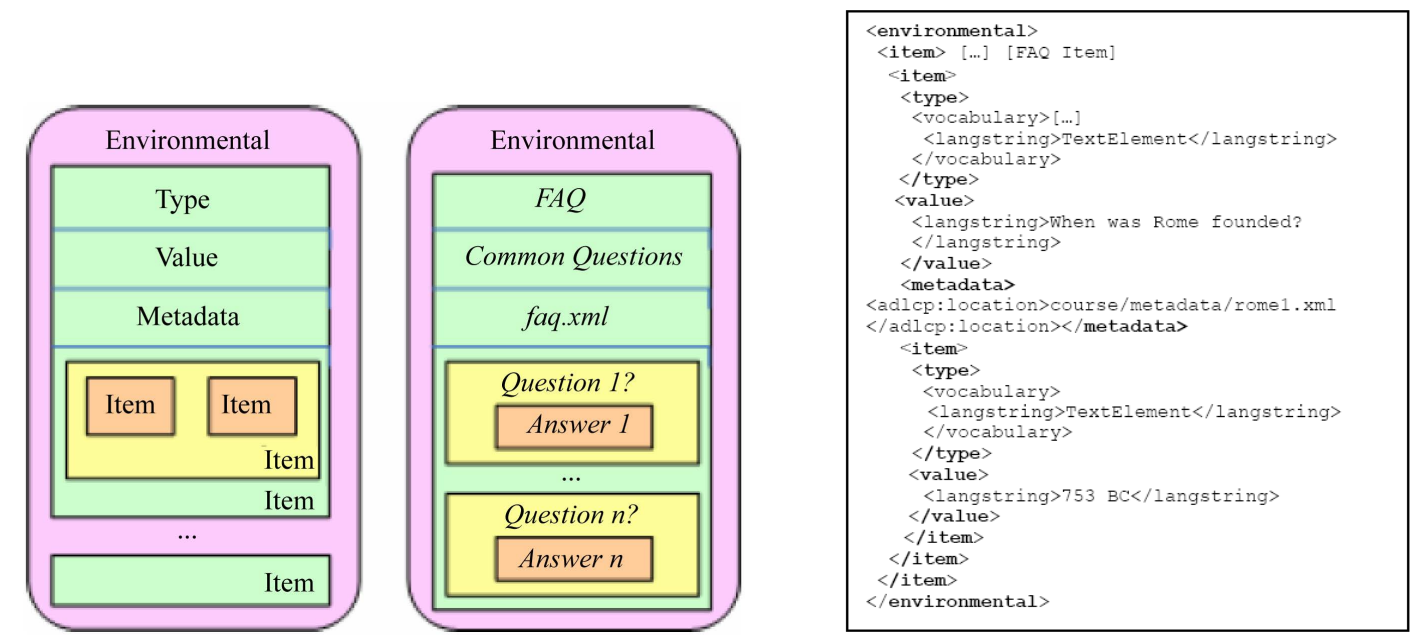

Figure 30. Application with the recursive item and xml code. Source: (Simoes, Luis, \& Horta, 2004).

\section{Future Research Directions}

In this Section, before we present the future research direction, we would like to present some contributions of this work.

The main contributions are:

- Creating an extension to the SCORM standard known as T-SCORM:

- The extension includes an adaptation of metadata information of the current SCORM standard based in LOM. This has improved the support for the search and navigation of LOs with educational content for t-Learning. For this reason, it was created a recommending process taking as parameter the information contained in the new metadata categories of the T-SCORM extension in the imsmanifest.xml compared the user profile information.

- Creating the authoring tool T-SCORM ADAPTER.

The T-SCORM ADAPTER tool was developed in order to facilitate the process of reading and adding of the T-SCORM extension proposed within the structure of the imsmanifest.xml file. This tool makes the addition process of the new metadata in a fast and simple way, i.e., the content creator does not need manually edit the imsmanifest.xml. This way, other metadata that were not identified in this work, but which are important in the iDTV area could easily be added.

- Creating the T-SCORM Moodle Application.

The T-SCORM Moodle application was created to work in integration with Moodle. Developed in the NCL and Lua languages, it operates in a virtual machine with the middleware Ginga-NCL, and performs the initial requesting process of videos with educational content with Moodle, which receives the requisition, treats and sends it the recommending response that is shown in the video options to be viewed by the user.

As future research directions, the work presented makes room for possible improvements and even innova- 
tions for the in applications developed and will certainly create other projects and publishing.

Some of the future work are:

- Review the categories of the T-SCORM extension and seek to improve the information level of the metadata always aiming at the main focus, which is to improve the search and navigation processes for LOs with educational content in the t-Learning platform.

- Implement new features in the authoring tool T-SCORM ADAPTER, e.g., whenever the user select a video resource which will have information added, the form that generates the information will show the last metadata configuration in the imsmanifest.xml handled previously. This will be useful to know how are the current metadata configuration and will be much faster for the content creator, in case he wishes only make small changes in the information.

- Creating a dynamic student profile. Currently, the user profile is static, i.e. the user provides the information. In dynamic profile, the information will be captured according to user interaction with the system interface.

- Increase the current videos recommending process taking into consideration, for instance, the relevance order. But for this, the system will identify which videos were most accessed, and it would you rate them depending on the user cognitive characteristics. At first, it could be considered think of using machine learning algorithms in order to improve the classification and suggestions of videos.

- Creating new versions of T-SCORM Moodle, implementing more features for tests in set top boxes and, in the same way, investigate access possibilities with multiple users in real time, with options for evaluations after the presentation of each LO, allowing its use by the community.

\section{Conclusion}

Along the last decade, it is remarkable growth of the Distance Education by means of excellent results, although it still presents huge challenges. One of these challenges is the spread of the Information and Communication Technology providing necessary infrastructure, for the Distance Education has taken a new direction by means of different hardware and software platforms, enabling the e-Learning, i.e., using the Internet for educational purposes.

Following this segment, the iDTV has also been an important factor in the communication and interaction for knowledge acquisition, entertainment and leisure in Distance Education context. This new teaching-learning has been called t-Learning. In this context, the LOs have an important role in helping in the electronic courses development.

The standardization of these LOs was created in order to allow the reusability of educational contents and systems interoperability, being the SCORM standard which was the most used for educational purposes. One of the major challenges of this work was to study and understand the SCORM, and based on this research, it was notices that it would be possible to create other extension profiles regarding the SCORM.

Thus, the T-SCORM extension was created by contemplating an adaptation of metadata information of current standard based on LOM, improving the support for search and navigation of Learning Objects with educational content for t-Learning.

Some difficulties in the project implementation were considered normal, once it was part of a knowledge process of a new technology. This kind of experience is essential for any development project to well succeed.

\section{Acknowledgements}

The authors thank CAPES for the financial support provided.

\section{References}

Aarreniemi-Jokipelto, P. (2005). T-Learning Model for Learning via Digital TV. 16th EAEEIE Annual Conference on Innovation in Education for Electrical and Information Engineering (EIE), Lappeenranta, 6-8 June 2005, 1.

ADL (2010). Advanced Distributed Learning. http://www.adlnet.org

Beck, R. J. (2008). What Are Learning Objects? Learning Objects, Milwaukee, WI: Center for International Education, University of Wisconsin-Milwaukee.

Bellotti, F. (2008). T-Learning Courses Development and Presentation Framework. IEEE Multidisciplinary Engineering Education Magazine, 3, 69-76. 
Bellotti, F., Vrochidis, S., Ramel, S., Tsampoulatidis, I., Lhoas, P., \& Pellegrino, M. (2008). A Technological Framework for the Authoring and Presentation of T-learning Courses. International Journal of Emerging Technologies in Learning, 3.

Doyle, M. (2009). Beginning PHP 5.3. Birmingham: Wrox Press Ltd.

Gazzoni, A., Canal, A. P., Falkembach, G. A. M., Fioreze, L. A., Pincolini, L. B., \& Antoniazzi, R. (2006). Proportionality and Similarity: Learning via Learning Objects. New Technologies in Education, 4.

http://seer.ufrgs.br/renote/article/viewFile/14141/8076

Girardi, R. (2002). Framework for Coordination and Mediation of Web Services Modeled as Learning Objects for Web Learning Environments. Master's Thesis, Rio de Janeiro: PUC-Rio.

Gomes, F. D. J. L. (2009). Exploring Learning Objects in Digital TV: A Case Study of Alternative Interaction. Doctorate Thesis, Porto Alegre: Federal University of Rio Grande do Sul (UFRS).

LTSC (2002). Learning Technologies Standards Committee. IEEE Standard 1484.12.1.

Lytras, M., Lougos, C., Chozos, P., \& Pouloudi, A. (2002). Interactive Television and E-Learning Convergence: Examining the Potential of T-Learning. European Conference on e-Learning 2002 (ECEL 2002), Brunel University, Uxbridge, 4-5 November 2002.

Naidu, S. (2006). E-Learning: A Guidebook of Principles, Procedures and Practices (2nd Revised ed.). New Delhi: Commonwealth Educational Media Center for Asia (CEMCA).

NISO (2004). Understanding Metadata. Bethesda, MD: NISO Press, National Information Standards Organization. http://www.niso.org/publications/press/UnderstandingMetadata.pdf

Pazos-Arias, J. J., López-Nores, M., García-Duque, J., Díaz-Redondo, R. P., Blanco-Fernández, Y., Ramos-Cabrer, M., Gil-Solla, A., \& Fernández-Vilas, A. (2008). Provision of Distance Learning Services over Interactive Digital TV with MHP. Computers \& Educatio, 50, 927-949. http://portal.acm.org/citation.cfm?id=1342427.1342676

Pontes, A. (2010). An Agents Architecture to Support Collaboration for Learning Problem-Based in Virtual Learning Environments. Master's Thesis, Mossoro: Federal University of Semi Arid (UFERSA).

Rey-Lopez, M., Diaz-Redondo, R. P., Fernandez-Vilas, A., Pazos-Arias, J. J., Garcia-Duque, J., Gil-Solla, A., \& RamosCabrer, M. (2009). An extension to the ADL SCORM Standard to Support Adaptivity: The t-Learning Case-Study. Computer Standards \& Interfaces, 31, 309-318. http://portal.acm.org/citation.cfm?id=1460931.1461076

Roebuck, K. (2012). Data Warehousing: High-Impact Strategies-What You Need To Know: Definitions, Adoptions, Impact, Benefits, Maturity, Vendors. Queensland: Emereo Publishing.

Shih, W.-C., Yang, C.-T., \& Tseng, S.-S. (2011). Fuzzy Folksonomy-Based Index Creation for e-Learning Content Retrieval on Cloud Computing Environments. 2011 IEEE International Conference on Fuzzy Systems (FUZZ), Taipei, 27-30 June 2011, 965-970.

Silva, F. M., Mendes Neto, F. M., Burlamaqui, A. M. F., \& Bezerra, D. H. D. (2012). T-SCORM: An Extension of the SCORM Standard to Support the Project of Educational Contents for t-Learning. Creative Education, 3, 101-108. http://dx.doi.org/10.4236/ce.2012.31017

Simoes, D., Luis, R., \& Horta, N. (2004). Enhancing the SCORM Modelling Scope. Proceedings of the IEEE International Conference on Advanced Learning Technologies, Joensuu, 30 August-1 September 2004, 880-881. http://dx.doi.org/10.1109/icalt.2004.1357701

Yin, R. K. (2005). Case Study: Planning and Methods 3. Brazil: Editora Bookman. 